\title{
Immunomodulatory dietary polysaccharides: a systematic review of the literature
}

\author{
Jane E Ramberg ${ }^{*}$, Erika D Nelson, Robert A Sinnott
}

\begin{abstract}
Background: A large body of literature suggests that certain polysaccharides affect immune system function. Much of this literature, however, consists of in vitro studies or studies in which polysaccharides were injected. Their immunologic effects following oral administration is less clear. The purpose of this systematic review was to consolidate and evaluate the available data regarding the specific immunologic effects of dietary polysaccharides.

Methods: Studies were identified by conducting PubMed and Google Scholar electronic searches and through reviews of polysaccharide article bibliographies. Only articles published in English were included in this review. Two researchers reviewed data on study design, control, sample size, results, and nature of outcome measures. Subsequent searches were conducted to gather information about polysaccharide safety, structure and composition, and disposition.

Results: We found 62 publications reporting statistically significant effects of orally ingested glucans, pectins, heteroglycans, glucomannans, fucoidans, galactomannans, arabinogalactans and mixed polysaccharide products in rodents. Fifteen controlled human studies reported that oral glucans, arabinogalactans, heteroglycans, and fucoidans exerted significant effects. Although some studies investigated anti-inflammatory effects, most studies investigated the ability of oral polysaccharides to stimulate the immune system. These studies, as well as safety and toxicity studies, suggest that these polysaccharide products appear to be largely well-tolerated.

Conclusions: Taken as a whole, the oral polysaccharide literature is highly heterogenous and is not sufficient to support broad product structure/function generalizations. Numerous dietary polysaccharides, particularly glucans, appear to elicit diverse immunomodulatory effects in numerous animal tissues, including the blood, Gl tract and spleen. Glucan extracts from the Trametes versicolor mushroom improved survival and immune function in human RCTs of cancer patients; glucans, arabinogalactans and fucoidans elicited immunomodulatory effects in controlled studies of healthy adults and patients with canker sores and seasonal allergies. This review provides a foundation that can serve to guide future research on immune modulation by well-characterized polysaccharide compounds.
\end{abstract}

\section{Background}

Polysaccharide-rich fungi and plants have been employed for centuries by cultures around the world for their dietary and medicinal benefits [1-5]. Often thought to merely support normal bowel function and blood glucose and lipid levels [6-8], certain polysaccharides have attracted growing scientific interest for their ability to exert marked effects on immune system function, inflammation and cancers [9-11]. Many of these chemi-

\footnotetext{
* Correspondence: jramberg@mannatech.com

Mannatech ${ }^{\mathrm{T}}$, Incorporated, 600 S. Royal Lane, Suite 200, Coppell, TX 75019
} USA

\section{Biomed Central}

(c) 2010 Ramberg et al; licensee BioMed Central Ltd. This is an Open Access article distributed under the terms of the Creative Commons Attribution License (http://creativecommons.org/licenses/by/2.0), which permits unrestricted use, distribution, and reproduction in any medium, provided the original work is properly cited. cally and structurally diverse, non- to poorly-digestible polysaccharides have been shown to beneficially affect one or more targeted cellular functions in vitro [11-16], but much of the in vivo literature consists of studies in which polysaccharides were injected $[1,2]$. For clinicians and scientists interested in immunologic effects following dietary intake, the value of such studies is uncertain. Polysaccharides that elicit effects in vitro or by injection may be ineffective or have different effects when taken orally [17]. We thus decided to conduct a systematic review to evaluate the specific immunologic effects of dietary polysaccharide products on rodents and human subjects. 


\section{Methods}

\section{Literature review}

Studies were identified by conducting electronic searches of PubMed and Google Scholar from their inception to the end of October 2009. The reference lists of the selected articles were checked for additional studies that were not originally found in the search.

\section{Study selection and data extraction}

The following search terms were combined with the term polysaccharide: dietary AND immune, or oral AND immune, or dietary AND inflammation, or oral AND inflammation. When specific polysaccharides or polysaccharide-rich plants and fungi were identified, further searches were conducted using their names with the same search terms. Studies were selected based on the following inclusion criteria:

1. Rodent or human studies

2. The presence of test group and control group (using either placebo, crossover, sham, or normal care)

3. Studies reporting statistically significant immunomodulatory effects

4. English language

5. Studies published up to October 2009.

Two researchers (JER, EDN) reviewed the list of unique articles for studies that fit the inclusion criteria. Uncertainties over study inclusion were discussed between the researchers and resolved through consensus. Searches were then conducted to obtain specific polysaccharide product information: safety (using the search terms: toxicity, NOAEL, $\mathrm{LD}_{50}$ ), composition and structure, and disposition.

\section{Quality assessment}

Each study was assessed as to whether or not it reported a significant outcome measure for the polysaccharide intervention group.

\section{Results}

A total of 62 rodent publications (Tables 1, 2 and 3) and 15 human publications (Table 4) were deemed appropriate for inclusion in this review. Available structural and compositional information for these immunomodulatory polysaccharides are provided in Table 5 and safety information is provided in Table 6 . The majority of animal studies explored models in which animals were injected or implanted with cancer cells or tumors, were healthy, or were exposed to carcinogens. Other studies investigated immunodeficient, exercise-stressed, aged animals, or animals exposed to inflammatory agents, viruses, bacterial pathogens, pathogenic protozoa, radiation or mutagens. Human studies assessed immunomodulatory effects in healthy subjects, or patients with cancers, seasonal allergic rhinitis or aphthous stomatitis. Because of the limited number of human studies, we included some promising open-label controlled trials. Human study durations ranged from four days to seven years; daily doses ranging from 100-5,400 mg were reported to be well-tolerated.

A number of studies in healthy human adults demonstrated immune stimulating effects of oral polysaccharides. Arabinogalactans from Larix occidentalis (Western larch) were shown in RCTs to increase lymphocyte proliferation and the number of CD8+ lymphocytes [18] and to increase the IgG subtype response to pneumococcal vaccination [19]. A furanose extract from Panax quiquefolium (North American ginseng) was shown in an RCT of healthy older adults to decrease the incidence of acute respiratory illness and symptom duration [20]. Finally, an RCT of healthy adults consuming Undaria pinnatifida (wakame) fucoidans found both immune stimulating and suppressing effects, including increased stromal-derived factor-1, IFN-g, CD34+ cells and CXCR4-expressing CD34+ cells and decreased blood leukocytes and lymphocytes [21].

Studies in healthy animals showed a number of immune stimulating effects of various glucan products from Agaricus subrufescens (A. blazei) (aqueous extracts [22], aqueous extracts with standardized $\beta$-glucans [23], $\alpha-1,6$ and $\alpha-1,4$ glucans [24], and whole plant powders [25]); Lentinula edodes (shiitake) (lentinan [26] and $\beta$ glucans [27]); Saccharomyces cerevisiae ( $\beta$-1,3-glucans $[27,28])$; Laminaria digitata (laminarin [29]); Sclerotium rofsii (glucan phosphate [29]); Sclerotinia sclerotiorum (SSG [30]); and Phellinus linteus (powder [31] and aqueous, alcohol-precipitated extract [32]). A furanose extract from $P$. quiquefolium and pectins from Buplerum falcatum and Malus (apple) spp. have also been shown to enhance immune function in healthy young animals [33-35]. Cyamopsis tetragonolobus galactomannan (guar gum) or highly methoxylated pectin feeding exerted numerous stimulating effects on antibody production in older animals [36].

Evidence for the effectiveness of oral polysaccharides against infection and immune challenges has been mainly demonstrated in animals. Immune stimulating effects have been shown in resting and exercise-stressed animals with thioglycollate, clodronate, or HSV-1 injections fed Avena (oat) spp. soluble glucans [37-41]; animals injected with or fed $E$. vermiformis and fed Avena spp. particulate glucans $[42,43]$; animals with $E$. coli injections fed L. digitata glucans (laminarin) [44]; animals with HSV injections fed $U$. pinnatifida fucoidans [45]; animals with Staphylococcus aureus or Candida 
Table 1 Immunomodulatory Glucan Extracts: Oral Animal Studies

\begin{tabular}{|c|c|c|c|c|c|c|c|}
\hline Source & Extract & Animal & Dose/day & $\begin{array}{l}\text { Duration } \\
\text { of study }\end{array}$ & Treatment & Effects & Reference \\
\hline \multirow[t]{10}{*}{$\begin{array}{l}\text { Agaricus } \\
\text { (A. blazei) } \\
\text { subrufescens }\end{array}$} & $\begin{array}{l}\alpha-1,6 \text { and } \\
\alpha-1,4 \\
\text { glucans }\end{array}$ & $\begin{array}{l}\text { 8-week o C C3H/ } \\
\text { He mice (5/ } \\
\text { group) }\end{array}$ & $\begin{array}{l}100 \mathrm{mg} / \mathrm{kg} \\
\mathrm{IG} \text { every } 3 \\
\text { days }\end{array}$ & 1 month & Healthy animals & $\begin{array}{l}\uparrow \text { \#s splenic T lymphocytes } \\
\text { (Thy } 1.2, \text { CD4+ and CD8+) }\end{array}$ & [24] \\
\hline & Aqueous & $\begin{array}{l}\text { 7-9-week on } \\
\text { Balb/cByJ mice } \\
\text { (40/group) }\end{array}$ & $\begin{array}{l}1 \mathrm{ml} 0.45 \mathrm{~N}, \\
0.6 \mathrm{~N} \text {, or } 3 \mathrm{~N} \\
\text { aqueous } \\
\text { extract }\end{array}$ & 2 months & & $\begin{array}{l}\text { All doses } \uparrow \text { serum lgG levels, } \\
\text { CD3+ T cell populations and } \\
\text { PML phagocytic activity }\end{array}$ & {$[22]$} \\
\hline & & $\begin{array}{l}\text { 7-9-week male } \\
\text { Balb/cByJ mice } \\
\text { (40/group) }\end{array}$ & $\begin{array}{l}1 \mathrm{ml} 0.45 \mathrm{~N}, \\
0.6 \mathrm{~N} \text {, or } 3 \mathrm{~N} \\
\text { aqueous } \\
\text { extract }\end{array}$ & 10 weeks & $\begin{array}{l}\text { IP injection of OVA at } 4 \\
\text { weeks }\end{array}$ & $\begin{array}{l}0.6 \mathrm{~N} \text { and } 3 \mathrm{~N} \uparrow \text { levels of OVA- } \\
\text { specific serum IgG } 28 \text { days } \\
\text { post-immunization; all doses } \\
\uparrow \text { delayed-type } \\
\text { hypersensitivity and TNF- } \alpha \\
\text { secreted from splenocytes at } \\
10 \text { weeks; } 0.6 \mathrm{~N} \uparrow \text { splenocyte } \\
\text { proliferation at } 10 \text { weeks }\end{array}$ & \\
\hline & & $\begin{array}{l}5-6 \text {-week } 9 \\
\text { BALB/cHsdOla } \\
\text { mice }(8 / \text { group } \\
\times 2)\end{array}$ & $\begin{array}{l}\text { One } 200 \mu l \\
\text { extract day } \\
1, \text { orogastric } \\
\text { intubation }\end{array}$ & 1 week & $\begin{array}{l}\text { Injected IP fecal solution day } \\
2\end{array}$ & $\begin{array}{l}\downarrow \text { CFU in blood of mice with } \\
\text { severe peritonitis \& improved } \\
\text { overall survival rate in all } \\
\text { peritonitis groups }\end{array}$ & {$[46]$} \\
\hline & & $\begin{array}{l}\text { 6-week BALB/C } \\
\text { nu/nu mice (7/ } \\
\text { group) }\end{array}$ & $\begin{array}{l}2.5 \mathrm{mg} \\
\text { extract days } \\
20-41 \\
\text { drinking } \\
\text { water }\end{array}$ & 41 days & $\begin{array}{l}\text { Injected SC Sp-2 myeloma } \\
\text { cells day } 1\end{array}$ & $\begin{array}{l}\downarrow \text { tumor size \& weight after } \\
21 \text { days treatment }\end{array}$ & {$[65]$} \\
\hline & $\begin{array}{l}\text { Aqueous, } \\
\text { acid treated }\end{array}$ & $\begin{array}{l}\text { 6-week } 9 \\
\text { C57BL/6 mice } \\
\text { (10/group) }\end{array}$ & $\begin{array}{l}20,100 \text { or } \\
500 \mu \mathrm{g} / \mathrm{ml}, \\
\text { drinking } \\
\text { water }\end{array}$ & 9 days & $\begin{array}{l}\text { Injected IP human ovarian } \\
\text { cancer cells day } 1\end{array}$ & $500 \mu \mathrm{g} / \mathrm{ml} \downarrow$ tumor weight & {$[66]$} \\
\hline & & & $\begin{array}{l}20,100 \text { or } \\
500 \mu \mathrm{g} / \mathrm{ml}, \\
\text { drinking } \\
\text { water }\end{array}$ & 3 weeks & $\begin{array}{l}\text { Injected IV murine lung } \\
\text { cancer ( } 3 \mathrm{LL}) \text { cells }\end{array}$ & $\begin{array}{l}100 \& 500 \mu \mathrm{g} / \mathrm{ml} \downarrow \text { \#s } \\
\text { metastatic tumors }\end{array}$ & \\
\hline & $\begin{array}{l}\text { Aqueous, } \\
\text { with } 200 \\
\text { ng/day } \\
\beta \text {-glucan }\end{array}$ & $\begin{array}{l}\text { 6-week o } \\
\text { BALB/c mice } \\
\text { (10/group) }\end{array}$ & $\begin{array}{l}200 \mathrm{ng} \text { days } \\
5-21\end{array}$ & 3 weeks & $\begin{array}{l}\text { Injected Meth A tumor cells } \\
\text { day } 1\end{array}$ & $\downarrow$ tumor size \& weight & [23] \\
\hline & & & & 2 weeks & Injected Meth A tumor cells & $\begin{array}{l}\uparrow \text { cytotoxic T lymphocyte } \\
\text { activity \& spleen cell IFN- } \alpha \\
\text { protein }\end{array}$ & \\
\hline & & & $300 \mathrm{mg}$ & 5 days & Healthy animals & $\uparrow$ splenic NK cell activity & \\
\hline \multirow[t]{4}{*}{ Avena spp. } & $\begin{array}{l}\beta \text {-glucans } \\
\text { (particulate) }\end{array}$ & $\begin{array}{l}\text { 6-7 -week o } \\
\text { C57BL/6 mice } \\
\text { (7/group) }\end{array}$ & $\begin{array}{l}3 \mathrm{mg} \text { every } \\
48 \mathrm{~h} \text {, days } \\
1-3\end{array}$ & 1 month & $\begin{array}{l}\text { Oral E. vermiformis oocytes } \\
\text { day } 10\end{array}$ & $\begin{array}{l}\downarrow \text { E. vermiformis fecal oocyte } \\
\text { \#s; increased intestinal anti- } \\
\text { merozoite IgA; } \downarrow \text { \# of IL-4- } \\
\text { secreting MLN cells }\end{array}$ & {$[42]$} \\
\hline & & & $\begin{array}{l}3 \text { mg on } \\
\text { alternating } \\
\text { days, days } \\
1-10\end{array}$ & 22 days & $\begin{array}{l}\text { Injected IP Eimeria } \\
\text { vermiformis day } 10\end{array}$ & $\begin{array}{l}\downarrow \text { E. vermiformis fecal oocyte } \\
\# \text { S; } \uparrow \text { anti-merozoite intestinal } \\
\operatorname{lgA}\end{array}$ & [43] \\
\hline & $\begin{array}{l}\beta \text {-glucans } \\
\text { (soluble) }\end{array}$ & $\begin{array}{l}\text { 4-week on CD-1 } \\
\text { mice (24/ } \\
\text { group) }\end{array}$ & $\begin{array}{l}0.6 \mathrm{mg} / \mathrm{ml} \\
68 \% \beta^{-} \\
\text {glucan, } \\
\text { drinking } \\
\text { water }\end{array}$ & 1 month & $\begin{array}{l}\text { Resting or exercise-stressed } \\
\text { (days 8-10) animals } \\
\text { administered HSV-1 IN } \\
\text { day } 10\end{array}$ & $\begin{array}{l}\downarrow \text { morbidity in resting and } \\
\text { exercise-stressed animals; } \downarrow \\
\text { mortality in exercise-stressed } \\
\text { animals; pre-infection, } \uparrow \text { Mø } \\
\text { anti-viral resistance in resting } \\
\text { and exercise-stressed animals }\end{array}$ & {$[38]$} \\
\hline & & & $\begin{array}{l}3.5 \mathrm{mg} \\
\text { days } \\
1-10 \\
\text { drinking } \\
\text { water }\end{array}$ & & $\begin{array}{l}\text { Resting or exercise-stressed } \\
\text { (days 5-10) animals } \\
\text { administered HSV-1 IN } \\
\text { day } 10\end{array}$ & $\begin{array}{l}\text { Pre-infection, } \uparrow M \varnothing \text { antiviral } \\
\text { resistance in resting animals }\end{array}$ & [41] \\
\hline
\end{tabular}


Table 1 Immunomodulatory Glucan Extracts: Oral Animal Studies (Continued)

\begin{tabular}{|c|c|c|c|c|c|c|c|}
\hline & & $\begin{array}{l}\text { 4-week o' CD-1 } \\
\text { mice (10/ } \\
\text { group) }\end{array}$ & $\begin{array}{l}0.6 \mathrm{mg} / \mathrm{ml} \\
68 \% \beta^{-} \\
\text {glucan, } \\
\text { drinking } \\
\text { water }\end{array}$ & 10 days & $\begin{array}{l}\text { Resting animals or animals } \\
\text { exposed to a bout of } \\
\text { fatiguing exercise days 8-10 } \\
\text { or moderate exercise days 5- } \\
\text { 10, injected IP with } \\
\text { thioglycollate on day } 10\end{array}$ & $\begin{array}{l}\uparrow \text { neutrophil mobilization in } \\
\text { resting \& moderately } \\
\text { exercised animals; } \uparrow \\
\text { neutrophil respiratory burst } \\
\text { activity in resting and } \\
\text { fatiguing exercised animals }\end{array}$ & [37] \\
\hline & & $\begin{array}{l}\text { 4-week o" CD-1 } \\
\text { mice (19-30/ } \\
\text { group) }\end{array}$ & $\begin{array}{l}0.8 \mathrm{mg} / \mathrm{ml} \\
50 \% \beta^{-} \\
\text {glucan, days } \\
1-10, \\
\text { drinking } \\
\text { water }\end{array}$ & 1 month & $\begin{array}{l}\text { Resting or exercise-stressed } \\
\text { (days 8-10) animals } \\
\text { administered IN clodronate- } \\
\text { filled liposomes to deplete } \\
\text { Mø days } 8 \text { \& } 14 \text { \& infected IN } \\
\text { with HSV-1 day } 10\end{array}$ & $\begin{array}{l}\downarrow \text { morbidity, mortality, } \\
\text { symptom severity in } \\
\text { exercise-stressed animals, } \\
\text { without Mø depletion }\end{array}$ & {$[40]$} \\
\hline & & $\begin{array}{l}\text { 4-week o" CD-1 } \\
\text { mice (20/ } \\
\text { group) }\end{array}$ & & & $\begin{array}{l}\text { Resting or exercise-stressed } \\
\text { (days 8-10) animals } \\
\text { administered HSV-1 IN day } \\
10\end{array}$ & $\begin{array}{l}\downarrow \text { morbidity in exercise- } \\
\text { stressed \& resting animals; } \downarrow \\
\text { mortality in exercise-stressed } \\
\text { animals }\end{array}$ & [39] \\
\hline \multirow[t]{2}{*}{$\begin{array}{l}\text { Ganoderma } \\
\text { lucidum }\end{array}$} & Aqueous & $\begin{array}{l}\text { 7-week o" CD-1 } \\
\text { mice (26/ } \\
\text { group) }\end{array}$ & $5 \%$ of diet & 5 months & $\begin{array}{l}\text { Injected IM DMH once a } \\
\text { week, weeks 1-10 }\end{array}$ & $\begin{array}{l}\downarrow \text { aberrant crypt foci per } \\
\text { colon, tumor size, cell } \\
\text { proliferation, nuclear staining } \\
\text { of } \beta \text {-catenin }\end{array}$ & {$[69]$} \\
\hline & & $\begin{array}{l}\text { 4-8-week } \\
\text { BALB/c mice } \\
\text { (10/group) }\end{array}$ & $\begin{array}{l}50,100 \text { or } \\
200 \mathrm{mg} / \mathrm{kg} \text {, } \\
\text { oral }\end{array}$ & 10 days & $\begin{array}{l}\text { Injected SD Sarcoma } 180 \\
\text { cells }\end{array}$ & $\begin{array}{l}\downarrow \text { of tumor weight was dose } \\
\text { dependent: } 27.7,55.8,66.7 \% \text {, } \\
\text { respectively }\end{array}$ & {$[67]$} \\
\hline $\begin{array}{l}\text { Ganoderma } \\
\text { lucidum } \\
\text { (mycelia) }\end{array}$ & Aqueous & $\begin{array}{l}\text { 7-week o" } \\
\text { F344/Du Crj } \\
\text { rats (16/group) }\end{array}$ & $\begin{array}{l}1.25 \% \text { or } \\
2.5 \% \text { of diet }\end{array}$ & 6 months & $\begin{array}{l}\text { Injected SC AOM once a } \\
\text { week, weeks } 2-5\end{array}$ & $\begin{array}{l}\text { Both doses } \downarrow \text { colonic } \\
\text { adenocarcinoma incidence; } \\
2.5 \% \downarrow \text { total tumor incidence; } \\
\text { both doses } \downarrow \text { nuclear } \\
\text { staining of } \beta \text {-catenin and cell } \\
\text { proliferation }\end{array}$ & {$[68]$} \\
\hline $\begin{array}{l}\text { Ganoderma } \\
\text { tsugae }\end{array}$ & Aqueous & $\begin{array}{l}\text { 8-week o } \\
\text { BALB/cByJNarl } \\
\text { mice (14/ } \\
\text { group) }\end{array}$ & $\begin{array}{l}0.2-0.4 \% \text { of } \\
\text { diet (young } \\
\text { fungi); } 0.33 \\
\text { or } 0.66 \% \text { of } \\
\text { diet (mature } \\
\text { fungi) }\end{array}$ & 5 weeks & $\begin{array}{l}\text { Injected IP OVA days 7, 14, } \\
21 \text {; aerosolized OVA twice } \\
\text { during week } 4\end{array}$ & $\begin{array}{l}\text { In splenocytes, both doses of } \\
\text { both extracts } \uparrow I \mathrm{IL}-2 \text { and IL-2/ } \\
\mathrm{IL}-4 \text { ratios, } 0.2 \% \text { young } \\
\text { extract and } 0.66 \% \text { mature } \\
\text { extract } \downarrow \mathrm{IL}-4 \text {; in } \mathrm{M} \varnothing, 0.66 \% \\
\text { mature extract } \uparrow \mathrm{IL}-1 \beta \text {, both } \\
\text { doses of both extracts } \uparrow \mathrm{IL}-6\end{array}$ & {$[53]$} \\
\hline \multirow[t]{2}{*}{ Grifola frondosa } & D fraction & $\begin{array}{l}\text { Mice: 1) ICR, 2) } \\
\text { C3H/HeN, 3) } \\
\mathrm{CDF}_{1}(10 / \\
\text { group) }\end{array}$ & $\begin{array}{l}1.5 \text { mg every } \\
\text { other day, } \\
\text { beginning } \\
\text { day } 2\end{array}$ & 13 days & $\begin{array}{l}\text { Implanted SC: 1) Sarcoma- } \\
\text { 180, 2) MM-46 carcinoma, or } \\
\text { 3) IMC carcinoma cells }\end{array}$ & $\begin{array}{l}\downarrow \text { tumor weight \& tumor } \\
\text { growth rate: 1) } 58 \%, 2 \text { 2) } 64 \% \text {, } \\
\text { and 3) } 75 \% \text {, respectively }\end{array}$ & {$[71]$} \\
\hline & & $\begin{array}{l}\text { 5-week on } \\
\text { BALB/c mice } \\
\text { (10/group) }\end{array}$ & $\begin{array}{l}2 \mathrm{mg} \\
\text { days } 15-30\end{array}$ & 45 days & $\begin{array}{l}\text { Injected in the back with 3- } \\
\text { MCA, day } 1\end{array}$ & $\begin{array}{l}\downarrow(62.5 \%) \# \text { of animals with } \\
\text { tumors; } \uparrow \mathrm{H}_{2} \mathrm{O}_{2} \text { production } \\
\text { by plasma } \mathrm{M} \varnothing ; \uparrow \text { cytotoxic } \top \\
\text { cell activity }\end{array}$ & {$[72]$} \\
\hline \multirow[t]{3}{*}{$\begin{array}{l}\text { Hordeum } \\
\text { vulgare }\end{array}$} & $\begin{array}{l}\beta-1,3 ; 1,4 \text { or } \\
\beta-1,3 ; 1,6-D- \\
\text { glucans }\end{array}$ & $\begin{array}{l}\text { Athymic nu/nu } \\
\text { mice } \\
\text { (4-12/group) }\end{array}$ & $\begin{array}{l}40 \text { or } 400 \mu g \\
\text { IG for } \\
4 \text { weeks }\end{array}$ & 31 weeks & $\begin{array}{l}\text { Mice with human xenografts } \\
\text { (SKMel28 melanoma, A431 } \\
\text { epidermoid carcinoma, BT474 } \\
\text { breast carcinoma, Daudi } \\
\text { lymphoma, or LAN-1 } \\
\text { neuroblastoma) } \pm \text { mAb (R24, } \\
528 \text {, Herceptin, Rituximab, or } \\
\text { 3F8, respectively) therapy } \\
\text { twice weekly }\end{array}$ & $\begin{array}{l}400 \mu g+\text { mAb } \downarrow \text { tumor } \\
\text { growth \& } \uparrow \text { survival; higher } \\
\text { MW } \downarrow \text { tumor growth rate for } \\
\text { both doses }\end{array}$ & {$[75]$} \\
\hline & $\begin{array}{l}\beta-1,3 ; 1,4-D- \\
\text { glucans }\end{array}$ & $\begin{array}{l}\text { Athymic BALB/ } \\
\text { c mice }\end{array}$ & $\begin{array}{l}4,40, \text { or } 400 \\
\mu g \text { for } 3- \\
4 \text { weeks }\end{array}$ & 1 month & $\begin{array}{l}\text { Mice with neuroblastoma } \\
\text { (NMB7, LAN-1, or SK-N-ER) } \\
\text { xenografts, } \pm 3 \text { F8 mAb } \\
\text { therapy twice weekly }\end{array}$ & $\begin{array}{l}40 \text { and } 400 \mu \mathrm{g} \text { doses }+\mathrm{mAB} \\
\downarrow \text { tumor growth; } 400 \mu \mathrm{gg} \\
\text { dose } \uparrow \text { survival. Serum NK } \\
\text { cells required for effects on } \\
\text { tumor size }\end{array}$ & {$[76]$} \\
\hline & & $\begin{array}{l}\text { C57BL/6 WT } \\
\text { and CR3- } \\
\text { deficient mice } \\
\text { (10/group) }\end{array}$ & $\begin{array}{l}0.4 \mathrm{mg} \text { for } \\
3 \text { weeks }\end{array}$ & 100 days & $\begin{array}{l}\text { Injected SC RMA-S-MUC1 } \\
\text { lymphoma cells day } 1 \pm \text { IV } \\
\text { 14.G2a or anti-MUC1 mAb } \\
\text { every 3rd day }\end{array}$ & $\begin{array}{l} \pm m A B \downarrow \text { tumor diameter; } \uparrow \\
\text { survival }\end{array}$ & {$[73]$} \\
\hline
\end{tabular}


Table 1 Immunomodulatory Glucan Extracts: Oral Animal Studies (Continued)

\begin{tabular}{|c|c|c|c|c|c|c|c|}
\hline & $\beta$-glucans & $\begin{array}{l}\text { O Fox Chase } \\
\text { ICR immune- } \\
\text { deficient (SCID) } \\
\text { mice ( } 9 / \text { group) }\end{array}$ & $\begin{array}{l}400 \mu \mathrm{g} \\
\text { days } 1-29\end{array}$ & 50 days & $\begin{array}{l}\text { Mice with human (Daudi, } \\
\text { EBV-BLCL, Hs445, or } \\
\text { RPMI6666) lymphoma } \\
\text { xenografts, } \pm \text { Rituximab mAb } \\
\text { therapy twice weekly }\end{array}$ & $\begin{array}{l}+m A B \downarrow \text { tumor growth and } \\
\uparrow \text { survival }\end{array}$ & {$[74]$} \\
\hline \multirow[t]{2}{*}{$\begin{array}{l}\text { Laminaria } \\
\text { digitata }\end{array}$} & \multirow[t]{2}{*}{ Laminarin } & $\begin{array}{l}\text { o' ICR/HSD } \\
\text { mice (3/group) }\end{array}$ & $1 \mathrm{mg}$ & 1 day & Healthy animals & $\begin{array}{l}\uparrow M \varnothing \text { expression of Dectin-1 } \\
\text { in GALT cells; } \uparrow \text { TLR2 } \\
\text { expression in Peyer's patch } \\
\text { dendritic cells }\end{array}$ & {$[29]$} \\
\hline & & $\begin{array}{l}\text { Ơ Wistar rats } \\
\text { (7/group) }\end{array}$ & $\begin{array}{l}5 \% \text { of diet } \\
\text { days } 1-4 \\
10 \% \text { of diet } \\
\text { days } 5-25\end{array}$ & 26 days & Injected IP E. coli LPS day 25 & $\begin{array}{l}\downarrow \text { liver ALT, AST, and LDH } \\
\text { enzyme levels; } \uparrow \text { ED2-positive } \\
\text { cells, } \downarrow \text { peroxidase-positive } \\
\text { cells in liver; } \downarrow \text { serum } \\
\text { monocytes, TNF- } \alpha, \text { PGE2, } \\
\mathrm{NO}_{2}\end{array}$ & {$[44]$} \\
\hline \multirow[t]{7}{*}{$\begin{array}{l}\text { Lentinula } \\
\text { edodes }\end{array}$} & SME & $\begin{array}{l}\text { 6-week nude } \\
\text { mice }\end{array}$ & $\begin{array}{l}0.1 \mathrm{ml} \text { water } \\
\text { with } 10 \% \\
\text { SME/10 g } \\
\text { body weight } \\
\text { days } 1-19, \\
33-50\end{array}$ & 50 days & $\begin{array}{l}\text { Injected SC prostate cancer } \\
\text { (PC-3) cells day } 1\end{array}$ & $\downarrow$ tumor size & {$[80]$} \\
\hline & \multirow[t]{2}{*}{$\beta$-glucans } & $\begin{array}{l}\text { o } 3-\text { and 8- } \\
\text { week BALB/C } \\
\text { mice (15/ } \\
\text { group) }\end{array}$ & $\begin{array}{l}50,100 \text { or } \\
250 \mu \mathrm{g}\end{array}$ & 1-2 weeks & Healthy animals & $\begin{array}{l}250 \mu \mathrm{g} \text { dose } \uparrow \text { spleen cell IL- } \\
2 \text { secretion }\end{array}$ & \multirow[t]{2}{*}{ [27] } \\
\hline & & $\begin{array}{l}\text { o 3- and 8- } \\
\text { week BALB/C } \\
\text { mice (15/ } \\
\text { group) }\end{array}$ & $\begin{array}{l}50,100 \text { or } \\
250 \mu g\end{array}$ & 1-2 weeks & $\begin{array}{l}\text { Injected murine mammary } \\
\text { carcinoma (Ptas64) cells into } \\
\text { mammary fat pads } 2 \text { weeks } \\
\text { before treatment }\end{array}$ & $\downarrow$ tumor weight & \\
\hline & \multirow[t]{4}{*}{ Lentinan } & $\begin{array}{l}\text { 6-week } \sigma^{\prime \prime} \\
\text { Wistar- } \\
\text { Imamichi } \\
\text { specific- } \\
\text { pathogen free } \\
\text { rats (10/group) }\end{array}$ & $\begin{array}{l}1 \text { mg twice } \\
\text { weekly }\end{array}$ & $\begin{array}{l}1-2 \\
\text { months }\end{array}$ & Healthy animals & $\begin{array}{l}\uparrow \top \text { cell \#s, helper-cell \#s \& } \\
\text { helper/suppressor ratio, } \downarrow \\
\text { suppressor cell level at } 4 \text {, but } \\
\text { not } 8 \text { weeks }\end{array}$ & [26] \\
\hline & & $\begin{array}{l}\text { 5-6-week ơ } \\
\text { pre-leukemic } \\
\text { AKR mice (10/ } \\
\text { group) }\end{array}$ & $\begin{array}{l}3 \text { mg, days } \\
1-7\end{array}$ & 3 weeks & $\begin{array}{l}\text { Injected SC K36 murine } \\
\text { lymphoma cells day } 7\end{array}$ & $\begin{array}{l}\downarrow \text { tumor weight; } \uparrow \text { tumor } \\
\text { inhibition rate }(94 \%)\end{array}$ & \multirow[t]{2}{*}[82]{} \\
\hline & & $\begin{array}{l}\text { 5-6-week } \\
\text { athymic mice } \\
\text { (10/group) }\end{array}$ & & 5 weeks & $\begin{array}{l}\text { Injected SC colon cancer } \\
\text { (LoVo and SW48, SW480 and } \\
\text { SW620, or SW403 and } \\
\text { SW1116) cells day } 7\end{array}$ & $\begin{array}{l}\downarrow \text { tumor weight, } \uparrow \text { tumor } \\
\text { inhibition rate }(>90 \%)\end{array}$ & \\
\hline & & or AKR mice & $3 \mathrm{mg}$ & 1 day & Pre-leukemic mice & $\begin{array}{l}\uparrow \text { serum IFN- } \alpha \text { and TNF- } \alpha \text {, } \\
\text { peak at } 4 h \text { and then back to } \\
\text { normal at } 24 \mathrm{~h} ; \uparrow I \mathrm{~L}-2 \text { and IL- } \\
1 \alpha \text {, peak at } 2 \mathrm{~h} \text { and back to } \\
\text { normal at } 24 \mathrm{~h} ; \uparrow \mathrm{CD} 3+\mathrm{T} \text {, } \\
\text { CD4+ T, CD } 8+\mathrm{T}, \mathrm{B} \\
\text { lymphocytes }\end{array}$ & {$[81]$} \\
\hline Phellinus linteus & $\begin{array}{l}\text { Aqueous, } \\
\text { alcohol- } \\
\text { precipitated }\end{array}$ & $\begin{array}{l}\text { 6-7-week } \\
\text { C57BL/6 mice } \\
\text { (10-50/group) }\end{array}$ & $\begin{array}{l}200 \mathrm{mg} / \mathrm{kg} \\
\text { in drinking } \\
\text { water }\end{array}$ & 1 month & Healthy animals & $\begin{array}{l}\uparrow \text { production and secretion } \\
\text { of IFN- } \gamma \text { by con A stimulated } \\
T \text { cells }\end{array}$ & {$[32]$} \\
\hline \multirow[t]{2}{*}{$\begin{array}{l}\text { Saccharomyces } \\
\text { cerevisiae }\end{array}$} & Scleroglucan & $\begin{array}{l}\sigma^{*} I C R / H S D \\
\text { mice (3/group) }\end{array}$ & $\begin{array}{l}1 \text { mg one } \\
\text { day before } \\
\text { challenge } \\
\text { (day 1) }\end{array}$ & 6 days & $\begin{array}{l}\text { IV Staphylococcus aureus or } \\
\text { Candida albicans day } 2\end{array}$ & $\uparrow$ long-term survival & {$[29]$} \\
\hline & $\begin{array}{l}\beta-1,3 ; 1,6 \\
\text { glucans } \\
\text { (particulate) }\end{array}$ & $\begin{array}{l}3 \text { and 8-week } \\
\text { o BALB/c mice } \\
\text { (15/group) }\end{array}$ & $\begin{array}{l}50,100 \text { or } \\
250 \mu \mathrm{g}\end{array}$ & 1-2 weeks & $\begin{array}{l}\text { Injected murine mammary } \\
\text { carcinoma (Ptas64) cells into } \\
\text { mammary fat pads } 2 \text { weeks } \\
\text { before treatment }\end{array}$ & $\downarrow$ tumor weight & [27] \\
\hline
\end{tabular}


Table 1 Immunomodulatory Glucan Extracts: Oral Animal Studies (Continued)

\begin{tabular}{|c|c|c|c|c|c|c|c|}
\hline & $\beta$-1,3-glucan & & & & Healthy animals & $\begin{array}{l}\text { All } 3 \text { doses } \uparrow \text { phagocytic } \\
\text { activity of blood monocytes } \\
\& \text { neutrophils \& } \uparrow \text { spleen cell } \\
\text { IL-2 secretion }\end{array}$ & \\
\hline & & $\begin{array}{l}\text { WT or } \\
\text { CCD11 } \mathrm{b}^{-/-} \\
\text {C57BL/6 mice } \\
\text { (2/group) }\end{array}$ & $\begin{array}{l}0.4 \mathrm{mg} \text { for } 3 \\
\text { weeks }\end{array}$ & 100 days & $\begin{array}{l}\text { Injected SC RMA-S-MUC1 } \\
\text { lymphoma cells } \pm 14 . G 2 \text { a or } \\
\text { anti-MUC1 mAb IV injection } \\
\text { every } 3^{\text {rd }} \text { day }\end{array}$ & $\begin{array}{l}\downarrow \text { tumor diameter when } \\
\text { included with mAb; } \uparrow \\
\text { survival with and without } \\
\text { mAb }\end{array}$ & {$[73]$} \\
\hline & & $\begin{array}{l}\text { C57BL/6mice } \\
\text { (4/group) }\end{array}$ & $25 \mathrm{mg}$ & 1 week & Healthy animals & $\begin{array}{l}\uparrow \# \text { intestinal IELs; } \uparrow \# \text { TCR } \alpha \beta \\
+, \mathrm{TCR} \gamma \delta+, \mathrm{CD} 8+, \mathrm{CD} 4+, \\
\mathrm{CD} 8 \alpha \alpha+, \mathrm{CD} 8 \alpha \beta+\mathrm{T} \text { cells in } \\
\text { IELs; } \uparrow \text { IFN- } \gamma \text { mRNA } \\
\text { expression in IELs and spleen }\end{array}$ & {$[28]$} \\
\hline $\begin{array}{l}\text { Sclerotinia } \\
\text { sclerotiorum }\end{array}$ & SSG & $\begin{array}{l}\text { 6-8-week } \\
\text { specific } \\
\text { pathogen-free } \\
\text { o' } \mathrm{CDF}_{1} \text { mice } \\
\text { (3/group) }\end{array}$ & $\begin{array}{l}40 \text { or } 80 \\
\mathrm{mg} / \mathrm{kg} \text { days } \\
1-10\end{array}$ & 2 weeks & Healthy animals & $\begin{array}{l}10 \text { mg dose } \uparrow \text { acid } \\
\text { phosphatase activity of } \\
\text { peritoneal Mø (day 14) }\end{array}$ & [30] \\
\hline & & & $\begin{array}{l}40,80 \text { or } 160 \\
\mathrm{mg} / \mathrm{kg} \text { days } \\
2-6\end{array}$ & 35 days & $\begin{array}{l}\text { Implanted SC Metha A } \\
\text { fibrosarcoma cells day } 1\end{array}$ & $80 \mathrm{mg}$ dose $\downarrow$ tumor weight & \\
\hline & & $\begin{array}{l}\text { 6-8-week } \\
\text { specific } \\
\text { pathogen-free } \\
\text { o" CDF } 1 \text { mice } \\
\text { (10/group) }\end{array}$ & $\begin{array}{l}40,80 \text { or } 160 \\
\mathrm{mg} / \mathrm{kg} \text { days } \\
2-11\end{array}$ & & $\begin{array}{l}\text { Injected ID IMC carcinoma } \\
\text { cells day } 1\end{array}$ & & \\
\hline & & $\begin{array}{l}\text { 6-8-week } \\
\text { specific- } \\
\text { pathogen free } \\
\text { o' mice of } \\
\text { BDF1 and } \\
\text { C57BL/6 mice } \\
\text { (7/group) }\end{array}$ & $\begin{array}{l}0.5,1,2, \text { or } 4 \\
\text { mg days } 1- \\
10\end{array}$ & $2-3$ weeks & $\begin{array}{l}\text { Injected IV Lewis lung } \\
\text { carcinoma ( } 3 L L) \text { cells }\end{array}$ & $\begin{array}{l}2 \mathrm{mg} \downarrow \text { \# of } 3 \mathrm{LL} \text { surface lung } \\
\text { nodules at } 2 \text { weeks }\end{array}$ & [83] \\
\hline Sclerotium rofsii & $\begin{array}{l}\text { Glucan } \\
\text { phosphate }\end{array}$ & $\begin{array}{l}\sigma^{\prime} I C R / H S D \\
\text { mice (3/group) }\end{array}$ & $1 \mathrm{mg}$ & 1 day & Healthy animals & $\begin{array}{l}\uparrow \text { systemic IL-6; } \uparrow \text { M } \varnothing \\
\text { expression of Dectin-1 in } \\
\text { GALT cells; } \uparrow \text { TLR2 expression } \\
\text { in dendritic cells from Peyer's } \\
\text { patches }\end{array}$ & [29] \\
\hline $\begin{array}{l}\text { Trametes } \\
\text { (Coriolus) } \\
\text { versicolor }\end{array}$ & PSP & $\begin{array}{l}\text { 6-8-week ơ } \\
\text { BALB/c mice } \\
\text { (10/group) }\end{array}$ & $\begin{array}{l}35 \mu \mathrm{g} \text { days } \\
5-29 \text { in } \\
\text { drinking } \\
\text { water }\end{array}$ & 29 days & $\begin{array}{l}\text { Implanted SC Sarcoma-180 } \\
\text { cells day } 1\end{array}$ & $\begin{array}{l}\downarrow \text { tumor growth \& vascular } \\
\text { density }\end{array}$ & [94] \\
\hline
\end{tabular}

albicans injections fed $S$. cerevisiae glucans (scleroglucan) [29]; and animals with fecal solution injections fed an aqueous extract of $A$. subrufescens (A. blazei Murrill) [46].

Additional controlled human and animal studies have shown anti-inflammatory and anti-allergy effects of some polysaccharide products. In an RCT of adults with seasonal allergic rhinitis, $S$. cerevisiae $\beta-1,3 ; 1-6$ glucans decreased IL-4, IL-5 and percent eosinophils, and increased IL-12 in nasal fluid [47], while a placebo-controlled study of patients with recurrent aphthous stomatitis (canker sores) consuming $\beta-1,3 ; 1-6$ glucans found increased lymphocyte proliferation and decreased Ulcer Severity Scores [48].

Animal models of inflammatory bowel disease have shown anti-inflammatory effects of Cladosiphon okamuranus Tokida fucoidans [49], Cyamopsis tetragonolobus galactomannans [50], Malus spp. pectins [51], and mixed polysaccharide supplements [52]. Animals challenged with ovalbumin have demonstrated anti-inflammatory/allergy effects of $A$. subrufescens aqueous extracts [22], an aqueous extract of Ganoderma tsugae [53], and Pyrus pyrifolia pectins [54]. Anti-inflammatory effects have also been seen in animals with cotton pellet implantations fed a Pholiota nameko heteroglycan (PNPS-1) [55].

Trametes versicolor glucans have demonstrated anticancer effects in humans. In two RCTs and five controlled trials, PSK from $T$. versicolor mycelia increased survival of advanced stage gastric, colon and colorectal cancer patients [56-62] with one study showing increased immune parameters (including blood NK cell activity, leukocyte cytotoxicity, proportion of helper cells 
Table 2 Immunomodulatory Non-Glucan Extracts: Oral Animal Studies

\begin{tabular}{|c|c|c|c|c|c|c|c|}
\hline Extract & Source & Animal & Oral dose/day & Duration & Treatment & Significant effects & Reference \\
\hline \multirow[t]{7}{*}{ Fucoidans } & $\begin{array}{l}\text { Cladosiphon } \\
\text { okamuranus } \\
\text { Tokida }\end{array}$ & $\begin{array}{l}\text { 8-week o BALB/c } \\
\text { mice, 10/group }\end{array}$ & $\begin{array}{l}0.05 \% \mathrm{w} / \mathrm{w} \text { of } \\
\text { diet }\end{array}$ & 56 days & DSS-induced UC & $\begin{array}{l}\downarrow \text { disease activity index and } \\
\text { myeloperoxidase activity; } \downarrow \\
\text { \# of B220-positive colonic B } \\
\text { cells; } \downarrow \text { colonic MLN IFN- } \gamma \\
\text { and IL-6 and } \uparrow \text { IL-10 and } \\
\text { TGF- } \beta ; \downarrow \text { colonic IgG; } \downarrow \\
\text { colonic epithelial cell IL-6, } \\
\text { TNF- } \alpha \text {, and TLR4 mRNA } \\
\text { expression }\end{array}$ & [49] \\
\hline & $\begin{array}{l}\text { Undaria } \\
\text { pinnatifida }\end{array}$ & $\begin{array}{l}\text { 5-week } 9 \text { BALB/c } \\
\text { mice (10-12/group) }\end{array}$ & $\begin{array}{l}5 \mathrm{mg} \text {, days } 1-14 \\
\text { or } 7-14\end{array}$ & 2 weeks & $\begin{array}{l}\text { Injected HSV into } \\
\text { cornea day } 7\end{array}$ & $\begin{array}{l}\downarrow \text { facial herpetic lesions; } \uparrow \\
\text { survival, particularly in pre- } \\
\text { treated animals }\end{array}$ & [45] \\
\hline & & & $10 \mathrm{mg}$ & 1 week & $\begin{array}{l}\text { Administered } \\
\text { 5-fluorouracil } \\
\end{array}$ & $\uparrow$ plasma NK cell activity & \\
\hline & & & & & Injected SC HSV & $\begin{array}{l}\uparrow \text { cytotoxic splenic } \mathrm{T} \\
\text { lymphocyte activity }\end{array}$ & \\
\hline & & & 0.1 or $0.5 \mathrm{mg}$ & 3 weeks & Injected IP HSV & $\begin{array}{l}\text { Both doses } \uparrow \text { serum } \\
\text { neutralizing Ab titers, } \\
\text { weeks } 2 \text { and } 3\end{array}$ & \\
\hline & & $\begin{array}{l}\text { 6-week on ddY mice } \\
\text { (5/group) }\end{array}$ & $\begin{array}{l}50,100,200400 \\
\text { or } \\
500 \mathrm{mg} / \mathrm{kg} \\
\text { days } 1-28\end{array}$ & 3 weeks & $\begin{array}{l}\text { Injected with Ehrlich } \\
\text { carcinoma in back } \\
\text { day } 14\end{array}$ & $\begin{array}{l}200-500 \mathrm{mg} / \mathrm{kg} \downarrow \text { tumor } \\
\text { growth }\end{array}$ & {$[116]$} \\
\hline & & $\begin{array}{l}\text { 6-week o" BALB/c } \\
\text { mice (8/group) }\end{array}$ & $\begin{array}{l}40 \mathrm{mg} / \mathrm{kg} \\
\text { alternating days } \\
7-19\end{array}$ & 19 days & $\begin{array}{l}\text { Injected IP Meth A } \\
\text { fibrosarcoma day } 1\end{array}$ & $\downarrow$ tumor growth & \\
\hline $\begin{array}{l}\text { Furanose } \\
\left(\text { COLD-FX }{ }^{\oplus}\right)\end{array}$ & $\begin{array}{l}\text { Panax } \\
\text { quinquefolium }\end{array}$ & $\begin{array}{l}\text { Weanling on SD rats } \\
\text { (10/group) }\end{array}$ & $\begin{array}{l}450 \text { or } \\
900 \mathrm{mg} / \mathrm{kg} \text { in } \\
\text { food }\end{array}$ & 1 week & Healthy animals & $\begin{array}{l}\text { Both doses } \uparrow \text { spleen II-2 } \\
\text { and IFN- } \gamma \text { production } \\
\text { following ConA or LPS } \\
\text { stimulation; } \downarrow \text { proportion of } \\
\text { total MLN and Peyer's } \\
\text { patch CD3+ cells \& } \\
\text { activated T cells; high dose } \\
\uparrow \text { spleen cell IL-1 } \beta \\
\text { production following } 48 \mathrm{~h} \\
\text { ConA stimulation. }\end{array}$ & {$[33]$} \\
\hline $\begin{array}{l}\text { Galacto- } \\
\text { mannan } \\
\text { (partially } \\
\text { hydrolyzed } \\
\text { guar gum) }\end{array}$ & $\begin{array}{l}\text { Cyamopsis } \\
\text { tetragonolobus }\end{array}$ & $\begin{array}{l}\text { 10-week o BALB/c } \\
\text { mice, } \\
\text { 11-15/group }\end{array}$ & $5 \%$ of diet & 3 weeks & $\begin{array}{l}\text { DSS-induced UC at } \\
\text { beginning of } \\
\text { week } 3\end{array}$ & $\begin{array}{l}\downarrow \text { disease activity index } \\
\text { scores, } \downarrow \text { colonic mucosal } \\
\text { myeloperoxidase activity \& } \\
\text { lipid peroxidation; } \downarrow \text { colonic } \\
\text { TNF- } \alpha \text { protein levels \& } \\
\text { mRNA expression up } \\
\text { regulated by DSS exposure }\end{array}$ & {$[50]$} \\
\hline $\begin{array}{l}\text { Galacto- } \\
\text { mannans } \\
\text { (guar gum) }\end{array}$ & & $\begin{array}{l}\text { 8-month- SD rats, } \\
\text { 5/group }\end{array}$ & $5 \%$ of diet & 3 weeks & Older animals & $\begin{array}{l}\downarrow \text { serum IgG; } \uparrow \mathrm{MLN} \\
\text { lymphocyte IgA, IgM and } \\
\text { lgG production }\end{array}$ & {$[36]$} \\
\hline \multirow[t]{2}{*}{$\begin{array}{l}\text { Glucomannan } \\
\text { (KS-2) }\end{array}$} & $\begin{array}{l}\text { Lentinula } \\
\text { edodes }\end{array}$ & $\begin{array}{l}\text { DD1 mice (10-20/ } \\
\text { group) }\end{array}$ & $\begin{array}{l}140 \mathrm{mg} / \mathrm{kg} \text { days } \\
2-13\end{array}$ & 50 days & $\begin{array}{l}\text { Injected IP Ehrlich } \\
\text { ascites tumor cells } \\
\text { day } 1\end{array}$ & $\uparrow$ survival & {$[84]$} \\
\hline & & & $\begin{array}{l}0.1,1,10, \text { or } 100 \\
\mathrm{mg} / \mathrm{kg} \text { dose days } \\
2-13\end{array}$ & 100 days & $\begin{array}{l}\text { Injected Sarcoma-180 } \\
\text { tumor cells } \\
\text { day } 1\end{array}$ & $\begin{array}{l}\text { 1, } 10 \text {, and } 100 \mathrm{mg} / \mathrm{kg} \\
\text { doses } \uparrow \text { survival }\end{array}$ & \\
\hline $\begin{array}{l}\text { Heteroglycan } \\
\text { (ATOM) }\end{array}$ & $\begin{array}{l}\text { A. } \\
\text { subrufescens }\end{array}$ & $\begin{array}{l}\text { Mice (10/group): 1) } \\
\text { 5-week O" Swiss/ } \\
\text { NIH; } 6 \text { week- O DS } \\
\text { mice; 3) 8-week o } \\
\text { BALB/c nude; 4) 5- } \\
\text { week C3H/HcN }\end{array}$ & $\begin{array}{l}100 \mathrm{or} \\
300 \mathrm{mg} / \mathrm{kg} \\
\text { days } 2-11\end{array}$ & 8 weeks & $\begin{array}{l}\text { Implanted SC 1) } \\
\text { Sarcoma-180, 2) } \\
\text { Shionogi carcinoma } \\
\text { 42, 3) Meth A } \\
\text { fibrosarcoma, or 4) } \\
\text { Ehrlich ascites } \\
\text { carcinoma cells }\end{array}$ & $\begin{array}{l}\text { Both doses } \downarrow \text { Sarcoma-180 } \\
\text { tumor size at } 4 \text { weeks \& } \uparrow \\
\text { survival; } 300 \mathrm{mg} / \mathrm{kg} \uparrow \\
\text { peritoneal macrophage and } \\
\text { C3-positive cells; } 300 \mathrm{mg} / \\
\mathrm{kg} \downarrow \text { Shionogi and Meth A } \\
\text { tumor sizes at } 4 \text { weeks. } \\
\text { Both doses } \uparrow \text { survival of } \\
\text { Ehrlich ascites mice }\end{array}$ & [93] \\
\hline
\end{tabular}


Table 2 Immunomodulatory Non-Glucan Extracts: Oral Animal Studies (Continued)

\begin{tabular}{|c|c|c|c|c|c|}
\hline $\begin{array}{l}\text { Heteroglycan } \\
\left(\mathrm{LBP}_{3 \mathrm{p}}\right)\end{array}$ & $\begin{array}{l}\text { Lycium } \\
\text { barbarum }\end{array}$ & $\begin{array}{l}\text { ơ Kunming mice } \\
\text { (10/group) }\end{array}$ & $\begin{array}{l}5,10 \mathrm{or} \\
20 \mathrm{mg} / \mathrm{kg}\end{array}$ & 10 days & $\begin{array}{l}\text { Injected SC Sarcom } \\
180 \text { cells }\end{array}$ \\
\hline
\end{tabular}

10 days Injected SC Sarcoma- $5 \& 10 \mathrm{mg} / \mathrm{kg} \uparrow$ thymus

index; all doses $\downarrow$ weight, $\downarrow$

lipid peroxidation in serum,

liver and spleen \& $\uparrow$ spleen lymphocyte proliferation,

cytotoxic T cell activity, IL-2 mRNA

\begin{tabular}{llllll}
\hline $\begin{array}{l}\text { Heteroglycan } \\
\text { (PNPS-1) }\end{array}$ & $\begin{array}{l}\text { Pholiota } \\
\text { nameko }\end{array}$ & SD rats (5/group) & $\begin{array}{l}100,200 \text { or } 400 \\
\mathrm{mg} / \mathrm{kg} \text { days } 1-8\end{array}$ & 8 days & $\begin{array}{l}\text { Implanted SC cotton } \\
\text { pellets in scapular } \\
\text { region } \\
\text { day } 1\end{array}$ \\
\hline $\begin{array}{llll}\text { Heteroglycan } \\
\text { (PG101) }\end{array}$ & $\begin{array}{l}\text { Lentinus } \\
\text { lepideus }\end{array}$ & $\begin{array}{l}\text { 8-10-week } \text { Q BALB/ } \\
\text { c mice (3/group) }\end{array}$ & $10 \mathrm{mg}$ & 24 days & $\begin{array}{l}6 \text { Gy gamma } \\
\text { irradiation }\end{array}$
\end{tabular}

$\downarrow$ granuloma growth positively correlated with dose: $11 \%, 18 \%$ and $44 \%$, respectively

(PG101) lepideus c mice (3/group)

$\uparrow$ colony forming cells,

granulocyte CFUs/Mø,

erythroid burst-forming

units, and myeloid

progenitor cells in bone

marrow; induced

proliferation of granulocyte

progenitor cells in bone

marrow; $\uparrow$ serum levels of

GM-CSF, IL-6, IL-1 $\beta$

\begin{tabular}{|c|c|c|c|}
\hline $\begin{array}{l}\text { Mixed poly- } \\
\text { saccharides } \\
\text { (Ambrotose }^{\circledR} \\
\text { or Advanced } \\
\text { Ambrotose }^{\circledR} \\
\text { powders) }\end{array}$ & $\begin{array}{l}\text { Aloe } \\
\text { barbadensis, } \\
\text { Larix spp, and } \\
\text { other plant } \\
\text { poly- } \\
\text { saccharides }\end{array}$ & $\begin{array}{l}\text { on SD rats (10/ } \\
\text { group) }\end{array}$ & $\begin{array}{l}37.7 \text { or } 377 \mathrm{mg} / \quad 2 \text { weeks } \\
\text { kg Ambrotose } \\
\text { powder or } 57.4 \\
\text { or } 574 \mathrm{mg} / \mathrm{kg} \\
\text { Advanced } \\
\text { Ambrotose } \\
\text { powder }\end{array}$ \\
\hline
\end{tabular}

5\% DSS in drinking $574 \mathrm{mg} / \mathrm{kg}$ Advanced

water beginning day Ambrotose powder $\downarrow$ DAl

scores; $377 \mathrm{mg} / \mathrm{kg}$

Ambrotose complex \&

both doses Advanced

Ambrotose powder $\uparrow$ colon

length and $\downarrow$ blood

monocyte count

\begin{tabular}{|c|c|c|c|c|c|}
\hline Pectin & Pyrus pyrifolia & $\begin{array}{l}\text { 6-8-week on BALB/C } \\
\text { mice (11/group) }\end{array}$ & $\begin{array}{l}100 \mu \mathrm{g} \\
\text { days } 1-7\end{array}$ & 22 days & $\begin{array}{l}\text { Injected IP OVA day } \\
7 \text {, provoked with } \\
\text { OVA aerosol day } 21\end{array}$ \\
\hline
\end{tabular}

bronchial fluid: $\downarrow$ IFN- $\gamma \& \uparrow$

IL-5; splenic cells: $\uparrow$ IFN- $\gamma$, $\downarrow$

IL-5; normalized pulmonary

histopathological changes;

$\downarrow$ serum $\lg \mathrm{E}$

\begin{tabular}{|c|c|c|c|c|c|c|c|}
\hline $\begin{array}{l}\text { Pectins } \\
\text { (bupleurum } \\
\text { 2llc) }\end{array}$ & $\begin{array}{l}\text { Bupleurum } \\
\text { falcatum }\end{array}$ & $\begin{array}{l}\text { 6-8-week } 9 \\
\text { specific-pathogen- } \\
\text { free } \mathrm{C} 3 \mathrm{H} / \mathrm{HeJ} \text { mice }\end{array}$ & $250 \mathrm{mg} / \mathrm{kg}$ & 1 week & Healthy animals & $\uparrow$ spleen cell proliferation & [35] \\
\hline $\begin{array}{l}\text { Pectins (highly } \\
\text { methoxylated) }\end{array}$ & Malus spp. & $\begin{array}{l}\text { 8-month- SD rats } \\
\text { (5/group) }\end{array}$ & $\begin{array}{l}5 \% \text { of diet vs. } \\
\text { cellulose control }\end{array}$ & 3 weeks & Older animals & $\begin{array}{l}\uparrow \text { MLN lymphocyte IgA \& } \\
\text { lgG }\end{array}$ & [36] \\
\hline \multirow[t]{5}{*}{ Pectins } & Citrus spp. & $\begin{array}{l}\text { 5-week o F344 rats } \\
\text { (30/group) }\end{array}$ & $15 \%$ of diet & 34 weeks & $\begin{array}{l}\text { Injected SC AOM } \\
\text { once a week, weeks } \\
4-14\end{array}$ & $\downarrow$ colon tumor incidence & [86] \\
\hline & Malus spp. & $\begin{array}{l}\text { 5-week o BALB/C } \\
\text { mice (6/group) }\end{array}$ & $5 \%$ of diet & 2 weeks & Healthy animals & $\begin{array}{l}\uparrow \text { fecal IgA and MLN CD4 } \\
+/ \text { CD8+ T lymphocyte ratio } \\
\& \text { IL-2 \& IFN- } \gamma \text { secretion by } \\
\text { ConA-stimulated MLN } \\
\text { lymphocytes }\end{array}$ & {$[51]$} \\
\hline & & $\begin{array}{l}\text { 5-week o BALB/C } \\
\text { mice (6/group) }\end{array}$ & $\begin{array}{l}5 \% \text { of diet days } \\
5-19 \text { vs. cellulose } \\
\text { control }\end{array}$ & 19 days & $\begin{array}{l}\text { DSS-induced UC days } \\
1-5\end{array}$ & $\begin{array}{l}\text { Significantly increased MLN } \\
\text { lymphocytes IgA, and } \\
\text { significantly decreased IgE; } \\
\text { significantly decreased } \\
\text { ConA-stimulated IL-4 and } \\
\text { IL-10 }\end{array}$ & \\
\hline & & $\begin{array}{l}\text { 4-week } 0^{x} \text { Donryu } \\
\text { rats (20-21/group) }\end{array}$ & $20 \%$ of diet & 32 weeks & $\begin{array}{l}\text { Injected SC AOM } \\
\text { once a week, } \\
\text { weeks 2-12 }\end{array}$ & $\downarrow$ colon tumor incidence & {$[85]$} \\
\hline & & $\begin{array}{l}\text { 4-week O" Donryu } \\
\text { rats (19-20/group) }\end{array}$ & $\begin{array}{l}10 \text { or } 20 \% \text { of } \\
\text { diet }\end{array}$ & 32 weeks & $\begin{array}{l}\text { Injected SC AOM } \\
\text { once a week, } \\
\text { weeks 2-12 }\end{array}$ & $\begin{array}{l}\text { Both doses } \downarrow \text { colon tumor } \\
\text { incidence; } 20 \% \downarrow \text { tumor } \\
\text { occupied area \& } \downarrow \text { portal } \\
\text { blood and distal colon } \\
\text { PGE }_{2}\end{array}$ & [90] \\
\hline
\end{tabular}


Table 2 Immunomodulatory Non-Glucan Extracts: Oral Animal Studies (Continued)

\begin{tabular}{|c|c|c|c|c|c|c|c|}
\hline \multirow[t]{4}{*}{$\begin{array}{l}\text { Pectins } \\
\text { (modified) }\end{array}$} & Citrus spp. & $\begin{array}{l}\text { 2-4-month BALB/c } \\
\text { mice (9-10/group) }\end{array}$ & $\begin{array}{l}0.8 \text { or } 1.6 \mathrm{mg} / \mathrm{ml} \\
\text { drinking water, } \\
\text { days } 8-20\end{array}$ & 20 days & $\begin{array}{l}\text { Injected SC with } 2 \times \\
2 \mathrm{~mm} \text { section of } \\
\text { human colon- } 25 \\
\text { tumor on day } 1\end{array}$ & Both doses $\downarrow$ tumor size & [87] \\
\hline & & $\begin{array}{l}\text { NCR nu/nu mice } \\
\text { (10/group) }\end{array}$ & $\begin{array}{l}1 \%(w / v) \\
\text { drinking water }\end{array}$ & 16 weeks & $\begin{array}{l}\text { Orthotopically } \\
\text { injected human } \\
\text { breast carcinoma } \\
\text { cells (MDA-MB-435) } \\
\text { into mammary fat } \\
\text { pad on day } 7\end{array}$ & $\begin{array}{l}\downarrow \text { tumor growth rate \& } \\
\text { volume at } 7 \text { weeks, lung } \\
\text { metastases at } 15 \text { weeks, \# } \\
\text { of blood vessels/tumor at } \\
33 \text { days post-injection }\end{array}$ & [89] \\
\hline & & $\begin{array}{l}\text { NCR nu/nu mice } \\
\text { (10/group) }\end{array}$ & $\begin{array}{l}1 \%(w / v) \\
\text { drinking water }\end{array}$ & 7 weeks & $\begin{array}{l}\text { Injected human } \\
\text { colon carcinoma cells } \\
\text { (LSLiL6) into cecum } \\
\text { on day } 7\end{array}$ & $\begin{array}{l}\downarrow \text { tumor weights and } \\
\text { metastases to the lymph } \\
\text { nodes and liver }\end{array}$ & \\
\hline & & SD rats (7-8/group) & $\begin{array}{l}0.01 \%, 0.1 \% \text { or } \\
1.0 \% \text { wt/vol of } \\
\text { drinking water, } \\
\text { days } 4-30\end{array}$ & 1 month & $\begin{array}{l}\text { Injected SC MAT-LyLu } \\
\text { rat prostate cancer } \\
\text { cells }\end{array}$ & $\begin{array}{l}0.1 \% \text { and } 1.0 \% \downarrow \text { lung } \\
\text { metastases; } 1.0 \% \downarrow \text { lymph } \\
\text { node disease incidence }\end{array}$ & [88] \\
\hline
\end{tabular}

Table 3 Immunomodulatory Polysaccharide-Rich Plant Powders: Oral Animal Studies

\begin{tabular}{|c|c|c|c|c|c|c|}
\hline Source & Animal & $\begin{array}{l}\text { Oral dose/ } \\
\text { day }\end{array}$ & Duration & Treatment & Significant effects & Reference \\
\hline $\begin{array}{l}\text { Agaricus (A. } \\
\text { blazei) } \\
\text { subrufescens } \\
\text { (fruit bodies) }\end{array}$ & $\begin{array}{l}\text { 6-week on } \\
\text { C57BL/6, C3H/ } \\
\text { HeJ and BALB/c } \\
\text { mice (3/group) }\end{array}$ & $\begin{array}{l}16,32 \text { or } 64 \\
\mathrm{mg}\end{array}$ & 2 weeks & Healthy animals & $\begin{array}{l}32 \text { and } 64 \text { mg } \uparrow \text { liver mononuclear cell } \\
\text { cytotoxicity }\end{array}$ & {$[25]$} \\
\hline $\begin{array}{l}\text { Grifola } \\
\text { frondosa }\end{array}$ & $\begin{array}{l}\text { 6-week o ICR } \\
\text { mice (10-15/ } \\
\text { group) }\end{array}$ & $5 \%$ of diet & 36 weeks & $\begin{array}{l}\text { Oral } \mathrm{N} \text {-butyl-N'- } \\
\text { butanolnitrosamine daily for first } 8 \\
\text { weeks }\end{array}$ & $\begin{array}{l}\downarrow \text { \#s of animals with bladder tumors; } \downarrow \\
\text { tumor weight; } \uparrow \text { peritoneal Mø } \\
\text { chemotactic activity, splenic } \\
\text { lymphocyte blastogenic response \& } \\
\text { cytotoxic activity }\end{array}$ & {$[70]$} \\
\hline $\begin{array}{l}\text { Laminaria } \\
\text { angustata }\end{array}$ & $\begin{array}{l}\text { Weanling SD } \\
\text { rats (58/group) }\end{array}$ & $5 \%$ of diet & 26 weeks & IG DMBA, beginning of week 5 & $\begin{array}{l}\uparrow \text { time to tumor development and } \downarrow \text { \# } \\
\text { of adenocarcinomas in } \\
\text { adenocarcinoma-bearing animals }\end{array}$ & {$[77]$} \\
\hline \multirow[t]{2}{*}{$\begin{array}{l}\text { Lentinula } \\
\text { (Lentinus) } \\
\text { edodes }\end{array}$} & $\begin{array}{l}\text { 6-week o ICR } \\
\text { mice (10-17/ } \\
\text { group) }\end{array}$ & $5 \%$ of diet & 36 weeks & Oral BBN daily for first 8 weeks & $\begin{array}{l}\downarrow \# \text { of animals with bladder tumors; } \downarrow \\
\text { tumor weight; } \uparrow \text { Mø chemotactic } \\
\text { activity, splenic lymphocyte blastogenic } \\
\text { response, cytotoxic activity }\end{array}$ & {$[70]$} \\
\hline & $\begin{array}{l}7-8 \text {-week } 0^{\prime \prime} \\
\text { Swiss mice (10/ } \\
\text { group) }\end{array}$ & $\begin{array}{l}1 \%, 5 \% \text { or } \\
10 \% \text { of diet of } \\
4 \text { different } \\
\text { lineages days } \\
1-15\end{array}$ & 16 days & $\begin{array}{l}\text { Injected IP N-ethyl-N-nitrosourea } \\
\text { day } 15\end{array}$ & $\begin{array}{l}\text { All } 3 \text { doses of one lineage and the } 5 \% \\
\text { dose of two other lineages } \downarrow \text { \#s of } \\
\text { micronucleated bone marrow } \\
\text { polychromatic erythrocytes }\end{array}$ & {$[79]$} \\
\hline \multirow[t]{4}{*}{$\begin{array}{l}\text { Lentinula } \\
\text { edodes (fruit } \\
\text { bodies) }\end{array}$} & $\begin{array}{l}\text { 5-week o ICR } \\
\text { mice } \\
(14 / \text { group } \times 2)\end{array}$ & $\begin{array}{l}10 \%, 20 \% \text { or } \\
30 \% \text { of diet }\end{array}$ & 25 days & Injected IP Sarcoma-180 ascites & $\begin{array}{l}\text { All } 3 \text { doses } \downarrow \text { Sarcoma-180 tumor } \\
\text { weight }\end{array}$ & {$[78]$} \\
\hline & $\begin{array}{l}\left.\text { Mice: 1) } \mathrm{CDF}_{1} ; 2\right) \\
\mathrm{C} 3 \mathrm{H} ; 3) \mathrm{BALB} / \mathrm{C} ; \\
4,5) \mathrm{C} 57 \mathrm{BL} / 6 \mathrm{~N} \\
(9 / \text { group } \times 3)\end{array}$ & $20 \%$ of diet & 25 days & $\begin{array}{l}\text { Injected SC 1) IMC carcinoma, 2) } \\
\text { MM-46 carcinoma, 3) Meth-A } \\
\text { fibrosarcoma, 4) B-16 melanoma, } \\
\text { or 5) Lewis lung carcinoma cells }\end{array}$ & $\begin{array}{l}\downarrow \text { growth of MM-46, B-16, Lewis lung, } \\
\text { and IMC tumors; } \uparrow \text { lifespan in Lewis } \\
\text { lung and MM-46 animals }\end{array}$ & \\
\hline & $\begin{array}{l}\text { ICR mice }(14 / \\
\text { group } \times 2)\end{array}$ & $\begin{array}{l}20 \% \text { of diet } \\
\text { days } 1-7 \text {, days } \\
7-31 \text { or days } \\
14-31\end{array}$ & 31 days & Injected IP Sarcoma-180 ascites & $\begin{array}{l}\downarrow \text { tumor weight \& growth when fed } \\
\text { days } 7-31 \text { or } 14-31\end{array}$ & \\
\hline & $\begin{array}{l}\left.\text { Mice: 1) } \mathrm{CDF}_{1} ; 2\right) \\
\mathrm{C} 3 \mathrm{H}(5 / \text { group } \\
\times 4)\end{array}$ & $20 \%$ of diet & $\begin{array}{l}\text { 7-12 } \\
\text { days }\end{array}$ & $\begin{array}{l}\text { Injected SC: 1) IMC carcinoma or } \\
\text { 2) MM-46 carcinoma cells }\end{array}$ & $\begin{array}{l}\uparrow \text { spreading rate of activated } M \varnothing \uparrow \\
\text { phagocytic activity }\end{array}$ & \\
\hline $\begin{array}{l}\text { Phellinus } \\
\text { linteus }\end{array}$ & $\begin{array}{l}\text { 4-week on ICR } \\
\text { mice (10/group) }\end{array}$ & $2 \mathrm{mg}$ & 1 month & Healthy animals & $\begin{array}{l}\downarrow \text { serum \& splenocyte lgE production; } \uparrow \\
\text { proportion of splenic CD } 4^{+} \text {T cells \& } \\
\text { splenocyte IFN- } \gamma \text { production }\end{array}$ & {$[31]$} \\
\hline $\begin{array}{l}\text { Pleurotus } \\
\text { ostreatus }\end{array}$ & $\begin{array}{l}\text { 6-week o ICR } \\
\text { mice } \\
\text { (10-20/group) }\end{array}$ & $5 \%$ of diet & 36 weeks & Oral BBN daily for first 8 weeks & $\begin{array}{l}\downarrow \text { \#s of animals with bladder tumors; } \downarrow \\
\text { tumor weight; } \uparrow \text { plasma Mø } \\
\text { chemotactic activity, splenic } \\
\text { lymphocyte blastogenic response, } \\
\text { cytotoxic activity }\end{array}$ & {$[70]$} \\
\hline
\end{tabular}


Table 4 Immunomodulatory Polysaccharide Products: Oral Human Studies

\begin{tabular}{|c|c|c|c|c|c|c|c|c|}
\hline Extract & Source & $\begin{array}{l}\text { Study } \\
\text { design }\end{array}$ & Population & $\begin{array}{l}\mathrm{N} \\
\text { (experimental/ } \\
\text { control) }\end{array}$ & Dose/day & $\begin{array}{l}\text { Dura- } \\
\text { tion }\end{array}$ & Significant effects & Reference \\
\hline $\begin{array}{l}\text { Arabino- } \\
\text { galactans }\end{array}$ & $\begin{array}{l}\text { Larix } \\
\text { occidentalis }\end{array}$ & $\begin{array}{l}\text { Randomized, } \\
\text { double-blind, } \\
\text { placebo- } \\
\text { controlled }\end{array}$ & Healthy adults & $8 / 15$ & $4 \mathrm{~g}$ & $\begin{array}{l}6 \\
\text { weeks }\end{array}$ & $\begin{array}{l}\uparrow \% \text { CD } 8+\text { lymphocytes \& } \\
\text { blood lymphocyte proliferation }\end{array}$ & [18] \\
\hline $\begin{array}{l}\text { Arabino- } \\
\text { galactans } \\
\left.\text { (ResistAid }^{T M}\right)\end{array}$ & & & $\begin{array}{l}\text { Healthy adults } \\
\text { given } \\
\text { pneumococcal } \\
\text { vaccinations } \\
\text { day } 30\end{array}$ & $21 / 24$ & $4.5 \mathrm{~g}$ & $\begin{array}{l}72 \\
\text { days }\end{array}$ & $\uparrow$ plasma lgG subtypes & [19] \\
\hline Fucoidans & $\begin{array}{l}\text { Undaria } \\
\text { pinnatifida } \\
\text { sporophylls }\end{array}$ & $\begin{array}{l}\text { Randomized, } \\
\text { single-blind, } \\
\text { placebo- } \\
\text { controlled }\end{array}$ & Healthy adults & $\begin{array}{l}25(75 \% \\
\text { fucoidan, } 6 \\
(10 \% \\
\text { fucoidan)/6 }\end{array}$ & $3 \mathrm{~g}$ & $\begin{array}{l}12 \\
\text { days }\end{array}$ & $\begin{array}{l}\text { 75\% fucoidan: } \downarrow \text { \#s blood } \\
\text { leukocytes, lymphocytes' } \uparrow \\
\text { plasma stromal derived factor- } \\
1, \text { IFN- } \gamma \text {, CD34+ cells; } \uparrow \% \\
\text { CXCR4-expressing CD34+ cells }\end{array}$ & [21] \\
\hline $\begin{array}{l}\text { Furanose } \\
\text { extract } \\
(\text { Cold-FX) }\end{array}$ & $\begin{array}{l}\text { Panax } \\
\text { quinque- } \\
\text { folium }\end{array}$ & $\begin{array}{l}\text { Randomized, } \\
\text { double-blind, } \\
\text { placebo- } \\
\text { controlled }\end{array}$ & $\begin{array}{l}\text { Healthy older } \\
\text { adults given } \\
\text { influenza } \\
\text { immunization at } \\
\text { the end of } \\
\text { week } 4\end{array}$ & $22 / 21$ & $400 \mathrm{mg}$ & $\begin{array}{l}4 \\
\text { months }\end{array}$ & $\begin{array}{l}\text { During weeks } 9-16, \downarrow \text { incidence } \\
\text { of acute respiratory illness, } \\
\text { symptom duration }\end{array}$ & [20] \\
\hline Glucans & $\begin{array}{l}\text { Agaricus } \\
\text { subru- } \\
\text { fescens }\end{array}$ & $\begin{array}{l}\text { Randomized, } \\
\text { double-blind, } \\
\text { placebo- } \\
\text { controlled }\end{array}$ & $\begin{array}{l}\text { Cervical, ovarian } \\
\text { or endometrial } \\
\text { cancer patients } \\
\text { receiving } 3 \\
\text { chemotherapy } \\
\text { cycles }\end{array}$ & $39 / 61$ & $\begin{array}{l}5.4 \mathrm{~g} \\
\text { (estimated) }\end{array}$ & $\begin{array}{l}6 \\
\text { weeks }\end{array}$ & $\begin{array}{l}\uparrow \text { NK cell activity, } \downarrow \\
\text { chemotherapy side effects }\end{array}$ & [64] \\
\hline $\begin{array}{l}\text { Glucans } \\
(\beta-1,3 ; 1,6)\end{array}$ & $\begin{array}{l}\text { Not } \\
\text { identified }\end{array}$ & $\begin{array}{l}\text { Placebo- } \\
\text { controlled }\end{array}$ & $\begin{array}{l}\text { Recurrent } \\
\text { aphthous } \\
\text { stomatitis } \\
\text { patients }\end{array}$ & $31 / 42$ & $20 \mathrm{mg}$ & $\begin{array}{l}20 \\
\text { days }\end{array}$ & $\begin{array}{l}\uparrow \mathrm{PBL} \text { lymphocyte } \\
\text { proliferation, } \downarrow \text { Ulcer Severity } \\
\text { Scores }\end{array}$ & [48] \\
\hline $\begin{array}{l}\text { Glucans } \\
(\beta-1,3 ; 1-6)\end{array}$ & S. cerevisiae & $\begin{array}{l}\text { Randomized, } \\
\text { double-blind, } \\
\text { placebo- } \\
\text { controlled }\end{array}$ & $\begin{array}{l}\text { Adults with } \\
\text { seasonal allergic } \\
\text { rhinitis }\end{array}$ & $12 / 12$ & $20 \mathrm{mg}$ & $\begin{array}{l}12 \\
\text { weeks }\end{array}$ & $\begin{array}{l}30 \text { minutes after nasal allergen } \\
\text { provocation test, nasal lavage } \\
\text { fluid: } \downarrow \text { IL-4, IL-5, \% eosinophils, } \\
\uparrow \text { IL-12 }\end{array}$ & {$[47]$} \\
\hline \multirow[t]{4}{*}{$\begin{array}{l}\text { Glucans } \\
\text { (PSK) }\end{array}$} & $\begin{array}{l}\text { Trametes } \\
\text { versicolor }\end{array}$ & $\begin{array}{l}\text { Randomized, } \\
\text { controlled }\end{array}$ & $\begin{array}{l}\text { Patients with } \\
\text { curatively } \\
\text { resected } \\
\text { colorectal cancer } \\
\text { receiving } \\
\text { chemotherapy }\end{array}$ & $221 / 227$ & $200 \mathrm{mg}$ & $\begin{array}{l}3-5 \\
\text { years }\end{array}$ & $\begin{array}{l}\uparrow \text { disease-free survival and } \\
\text { overall survival }\end{array}$ & [56] \\
\hline & & Controlled & $\begin{array}{l}\text { Post-surgical } \\
\text { colon cancer } \\
\text { patients receiving } \\
\text { chemotherapy }\end{array}$ & $123 / 121$ & $\begin{array}{l}3 \mathrm{~g} \text { for } 4 \\
\text { weeks, } \\
\text { alternating } \\
\text { with } 104- \\
\text { week courses } \\
\text { of chemo- } \\
\text { therapy }\end{array}$ & 7 years & $\begin{array}{l}\uparrow \text { survival from cancer deaths; } \\
\text { no difference in disease-free or } \\
\text { overall survival }\end{array}$ & {$[57]$} \\
\hline & & & $\begin{array}{l}\text { Post-surgical } \\
\text { colorectal cancer } \\
\text { patients receiving } \\
\text { chemotherapy }\end{array}$ & $137 / 68$ & $3 \mathrm{~g}$ daily & 2 years & $\begin{array}{l}\uparrow \text { survival in stage III patients; } \downarrow \\
\text { recurrence in stage II \& III } \\
\text { patients }\end{array}$ & [58] \\
\hline & & & $\begin{array}{l}\text { Post-surgical } \\
\text { gastric cancer } \\
\text { patients receiving } \\
\text { chemotherapy }\end{array}$ & $124 / 129$ & $\begin{array}{l}3 \mathrm{~g} \text { for } 4 \\
\text { weeks, } \\
\text { alternating } \\
\text { with } 104- \\
\text { week courses } \\
\text { of chemo- } \\
\text { therapy }\end{array}$ & $\begin{array}{l}5-7 \\
\text { years }\end{array}$ & $\begin{array}{l}\uparrow 5 \text {-year disease-free survival } \\
\text { rate, overall 5-year survival }\end{array}$ & [59] \\
\hline
\end{tabular}


Table 4 Immunomodulatory Polysaccharide Products: Oral Human Studies (Continued)

\begin{tabular}{|c|c|c|c|c|c|c|c|c|}
\hline & & & $\begin{array}{l}\text { Pre-surgical } \\
\text { gastric or } \\
\text { colorectal cancer } \\
\text { patients }\end{array}$ & $\begin{array}{l}16 \text { daily; } 17 \\
\text { every other } \\
\text { day/13 }\end{array}$ & $\begin{array}{l}3 \mathrm{~g} \text { daily or on } \\
\text { alternate days } \\
\text { before surgery }\end{array}$ & $\begin{array}{l}<14 \\
\text { days or } \\
14-36 \\
\text { days }\end{array}$ & $\begin{array}{l}\geq 14 \text { day treatment: } \uparrow \\
\text { peripheral blood NK cell } \\
\text { activity, PBL cytotoxicity, } \\
\text { proportion of PBL helper cells; } \\
\downarrow \text { proportion of PBL inducer } \\
\text { cells; <14 day treatment: } \uparrow \text { PBL } \\
\text { response to PSK and Con A, } \\
\text { proportion of regional node } \\
\text { lymphocyte suppressor cells }\end{array}$ & {$[62]$} \\
\hline & & $\begin{array}{l}\text { Randomized, } \\
\text { double-blind, } \\
\text { placebo- } \\
\text { controlled }\end{array}$ & $\begin{array}{l}\text { Post-surgical } \\
\text { stage III-IV } \\
\text { colorectal cancer } \\
\text { patients }\end{array}$ & $56 / 55$ & $\begin{array}{l}3 \mathrm{~g} \text { for } 2 \\
\text { months, } 2 \mathrm{~g} \\
\text { for } 22 \text { months, } \\
1 \mathrm{~g} \text { thereafter }\end{array}$ & $\begin{array}{l}8-10 \\
\text { years }\end{array}$ & $\uparrow$ remission \& survival rates & {$[61]$} \\
\hline & & Controlled & $\begin{array}{l}\text { Post-surgical } \\
\text { stage III gastric } \\
\text { cancer patients } \\
\text { receiving } \\
\text { chemotherapy }\end{array}$ & $32 / 21$ & $3 \mathrm{~g}$ & 1 year & $\uparrow$ survival time & {$[60]$} \\
\hline $\begin{array}{l}\text { Glucans } \\
\text { (PSP) }\end{array}$ & $\begin{array}{l}\text { Trametes } \\
\text { versicolor }\end{array}$ & $\begin{array}{l}\text { Randomized, } \\
\text { double-blind, } \\
\text { placebo- } \\
\text { controlled }\end{array}$ & $\begin{array}{l}\text { Conventionally- } \\
\text { treated stage III- } \\
\text { IV non-small cell } \\
\text { lung cancer } \\
\text { patients }\end{array}$ & $34 / 34$ & $3.06 \mathrm{~g}$ & $\begin{array}{l}1 \\
\text { month }\end{array}$ & $\begin{array}{l}\uparrow \text { blood lgG \& IgM, total } \\
\text { leukocyte and neutrophil } \\
\text { counts, } \% \text { body fat; } \downarrow \text { patient } \\
\text { withdrawal due to disease } \\
\text { progression }\end{array}$ & {$[63]$} \\
\hline
\end{tabular}

and lymphocyte suppressor cells) [62]. An RCT of advanced stage lung cancer patients consuming PSP from T. versicolor fruit bodies found increased IgG and IgM antibodies and total leukocyte and neutrophil counts, along with a decrease in the number of patients withdrawing from the study due to disease progression [63]. An RCT of ovarian or endometrial cancer patients consuming A. subrufescens glucans showed increased NK cell activity and fewer chemotherapy side effects [64].

In numerous animal models of cancer, a wide range of polysaccharides have shown anti-tumorogenic effects. Glucan products sourced from $A$. subrufescens demonstrating anti-cancer activities in animal models include an aqueous extract [65], an aqueous, acid-treated extract [66], and an aqueous extract with standardized levels of $\beta$-glucans [23]. Anti-cancer effects have been reported following intake of aqueous extracts of G. lucidum [67-69]; the powder and D fraction of G. frondosa [70-72]; Hordeum vulgare $\beta$-glucans [73-76]; Laminaria angustata powder [77]; Lentinula edodes products (powders [70,78,79], SME [80], $\beta$-glucans [27], and lentinan $[81,82]) ;$ Pleurotus ostreatus powder [70], Saccharomyces cerevisiae particulate $\beta-1,3 ; 1,6$ and $\beta-1,3$ glucans $[27,73]$; and a glucan from Sclerotinia sclerotiorum (SSG) [30,83]. A glucomannan from L. edodes (KS-2) improved survival of animals with cancer cell injections [84]; apple and citrus pectins have exerted anti-cancer effects, including decreased tumor incidence [85-90]. Finally, heteroglycans from Lycium barbarum $\left(\mathrm{LBP}_{3 \mathrm{p}}\right)$, Lentinus lepidus (PG101) and A. subrufescens (ATOM) demonstrated a number of immune stimulating effects in animal cancer models [91-93]. Interestingly, only one animal study has been performed using glucans from $T$. versicolor (PSP): animals with cancer cell implantations showed decreased tumor growth and vascular density [94].

Most polysaccharide products appear to be safe, based on NOAEL, acute and/or chronic toxicity testing in rodents (Table 6). As would be expected, powders, extracts and products that have not been fully characterized pose the most concerns. Other than for aloe vera gel, which was shown in a small human trial to increase the plasma bioavailability of vitamins $C$ and $E$ [95], the impact of polysaccharide intake on the absorption of nutrients and medications is not known. While one rat toxicity study raised concerns when guar gum comprised $15 \%$ of the daily diet [96], the product was safe in humans studies when 18-39.6 g/day was consumed for up to a year (Table 4). Product contamination may explain three case reports of hepatotoxicity and/or death following intake of an A. subrufescens aqueous extract [97]. Seven animal studies reporting positive immunologic effects of $A$. subrufescens extracts in healthy animals or animals with cancers found no evidence of toxicity (Tables 1 and 2). In humans, six weeks of $A$. subrufescens glucans intake was safe for cancer patients, and four months of $3 \mathrm{~g} /$ day intake by 24 healthy adults and 24 adults with liver disease reported no evidence of toxicity (Table 4). Another case report associated liver toxicity with G. lucidum intake, but the elderly subject also took an unidentified product a month previous to her admission for testing [98]. Three animal studies reported immunologic benefits and no adverse effects 
Table 5 Immunomodulatory Polysaccharide Products: Composition and Structure

\begin{tabular}{|c|c|c|c|c|c|}
\hline Source & Category & Features & MW & $\begin{array}{l}\text { Monosaccharide } \\
\text { composition }\end{array}$ & Reference \\
\hline Agaricus subrufescens (A. blazei) & Extract & $\beta$-1,6-D-glucan & 10,000 & NA & {$[66]$} \\
\hline \multirow[t]{2}{*}{ Agaricus subrufescens (fruit body) } & Extract & $\begin{array}{l}\alpha-1,6-\text { and } \alpha-1,4 \text { glucans with } \\
\beta-1,6-\text { glucopyranosyl backbone } \\
(629.2 \mathrm{mcg} / \mathrm{mg} \text { polysaccharides, } \\
43.5 \mathrm{mcg} / \mathrm{mg} \text { protein) }\end{array}$ & 170,000 & glucose & {$[24]$} \\
\hline & & $\begin{array}{l}\alpha-1,4 \text { glucans } \& \beta-1,6 \text { glucans } \\
\text { with } \beta-1,3 \text { side branches; } \alpha-1,6 \\
\text { glucans; } \beta-1,6 ; 1-3 \text { glucans, } \beta-1,4 \\
\text { glucans; } \beta-1,3 \text { glucans; } \beta-1,6 ; \alpha- \\
1,3 \text { glucans; riboglucans, } \\
\text { galactoglucomannans, } \beta-1,2 ; \beta \text { - } \\
\text { 1,3 glucomannans }\end{array}$ & NA & $\begin{array}{l}\text { glucose, mannose, galactose, } \\
\text { ribose }\end{array}$ & {$[25,117,118]$} \\
\hline Agaricus subrufescens (mycelia) & $\begin{array}{l}\text { Extract } \\
\text { (ATOM) }\end{array}$ & $\begin{array}{l}\beta-1,6-\mathrm{D}-\text { glucan, protein } \\
\text { complex, } 5 \% \text { protein }\end{array}$ & $100,000-1,000,000$ & $\begin{array}{l}\text { glucose, mannose, galactose, } \\
\text { ribose }\end{array}$ & [93] \\
\hline \multirow[t]{4}{*}{ Aloe barbadensis (leaf gel) } & Whole tissue & $\begin{array}{l}\text { Dry weight: } 10 \% \\
\text { polysaccharides; acemannan, } \\
\text { aloemannan, aloeride, pectic } \\
\text { acid, galactans, arabinans, } \\
\text { glucomannans }\end{array}$ & $\begin{array}{l}\text { average } \\
2,000,000\end{array}$ & $\begin{array}{l}\text { mannose, glucose, galactose, } \\
\text { arabinose, xylose, rhamnose }\end{array}$ & {$[119,120]$} \\
\hline & $\begin{array}{l}\text { Extract } \\
\text { (aloemannan) }\end{array}$ & $\begin{array}{l}\text { neutral partially acetylated } \\
\text { glucomannan, mainly } \beta-1,4- \\
\text { mannans }\end{array}$ & $>200,000$ & mannose, glucose & {$[121]$} \\
\hline & $\begin{array}{l}\text { Extract } \\
\text { (aloeride) }\end{array}$ & NA & $\begin{array}{l}4,000,000- \\
7,000,000\end{array}$ & $\begin{array}{l}37 \% \text { glucose, } 23.9 \% \\
\text { galactose, } 19.5 \% \text { mannose, } \\
10.3 \% \text { arabinose }\end{array}$ & [122] \\
\hline & $\begin{array}{l}\text { Extract } \\
\text { (acemannan) }\end{array}$ & $\beta-1,4$ acetylated mannan & 80,000 & mannose & [123] \\
\hline $\begin{array}{l}\text { Aloe barbadensis, (leaf gel), Larix } \\
\text { sp. (bark), Anogeissus latifolia } \\
\text { (bark), Astragalus gummifer } \\
\text { (stem), Oryza sativa (seed), } \\
\text { glucosamine }\end{array}$ & $\begin{array}{l}\text { Extracts } \\
\text { (Ambrotose }{ }^{\oplus} \\
\text { powder) }\end{array}$ & $\begin{array}{l}\beta-1,4 \text { acetylated mannan, } \\
\text { arabinogalactans, } \\
\text { polysaccharide gums, rice } \\
\text { starch, } 5.4 \% \text { protein }\end{array}$ & $\begin{array}{l}57.3 \% \geq 950,000 \\
26.4 \%<950,000 \\
\text { and } \geq 80,000 \\
16.3 \% \leq 10,000\end{array}$ & $\begin{array}{l}\text { mannose, galactose, } \\
\text { arabinose, glucose, } \\
\text { galacturonic acid, rhamnose, } \\
\text { xylose, fructose, fucose, } \\
\text { glucosamine, galacturonic } \\
\text { acid }\end{array}$ & $\begin{array}{l}\text { (unpublished } \\
\text { data, } \\
\text { Mannatech } \\
\text { Incorporated) }\end{array}$ \\
\hline $\begin{array}{l}\text { Aloe barbadensis (leaf gel), Larix } \\
\text { sp. (bark), Undaria pinnatifida } \\
\text { (frond), Anogeissus latifolia (bark), } \\
\text { Astragalus gummifer (stem), } \\
\text { Oryza sativa (seed), glucosamine }\end{array}$ & $\begin{array}{l}\text { Extracts } \\
\text { (Advanced } \\
\text { Ambrotose } \\
\text { powder) }\end{array}$ & $\begin{array}{l}\beta-1,4 \text { acetylated mannan, } \\
\text { arabinogalactans, } \\
\text { polysaccharide gums, fucoidans, } \\
\text { rice starch, } 6 \% \text { protein, } 1 \% \text { fatty } \\
\text { acids }\end{array}$ & $\begin{array}{l}13 \%=1,686,667 \\
46 \%=960,000 \\
30 \%<950,000 \\
\text { and } \geq 70,000 \\
11 \% \leq 10,000\end{array}$ & & \\
\hline Avena spp. (seed endosperm) & Extract & $\begin{array}{l}\beta-1,3 ; 1,4 \text { particulate }(1-3 \mu) \\
\text { glucans }\end{array}$ & $1,100,000$ & glucose & [43] \\
\hline Avena spp. (seed) & Extract & $\begin{array}{l}\beta-1,4,1,3 \text { particulate glucans } \\
\text { (linear chains of } \beta \text {-D- } \\
\text { glycopyranosyl units; } 70 \% \beta \quad \text { 1-4 } \\
\text { linked) }\end{array}$ & $2,000,000$ & $\mathrm{NA}$ & {$[41,124]$} \\
\hline Buplerum falcatum (root) & $\begin{array}{l}\text { Extract } \\
\text { (bupleuran } \\
\text { 2llc) }\end{array}$ & $\begin{array}{l}6 \text { linked galactosyl chains with } \\
\text { terminal glucuronic acid } \\
\text { substituted to } \beta \text {-galactosyl } \\
\text { chains }\end{array}$ & NA & $\begin{array}{l}\text { galactose, glucuronic acid, } \\
\text { rhamnose }\end{array}$ & [35] \\
\hline Citrus spp. (fruit) & Extract & $\begin{array}{l}\alpha-1,4-\text { linked partially esterified } \\
\text { D-anhydrogalacturonic acid } \\
\text { units interrupted periodically } \\
\text { with 1,2-rhamnose }\end{array}$ & $70,000-100,000$ & $\begin{array}{l}\text { galactose, galacturonic acid, } \\
\text { arabinose, glucose, xylose, } \\
\text { rhamnose }\end{array}$ & {$[125]$} \\
\hline Cladosiphon okamuranus (frond) & Extract & $\alpha-1,3-$ fucopyranose sulfate & 56,000 & $\begin{array}{l}\text { fucose:glucuronic acid } \\
(6.1: 1.0)\end{array}$ & {$[126]$} \\
\hline Cordyceps sinensis (mycelia) & Extract & $\begin{array}{l}\beta-1,3-D-g l u c a n \text { with } 1,6- \\
\text { branched chains }\end{array}$ & NA & NA & [127] \\
\hline Cyamopsis tetragonolobus (seed) & $\begin{array}{l}\text { Extract (guar } \\
\text { gum) }\end{array}$ & $\begin{array}{l}\text { Main chain of } \beta-1,4- \\
\text { mannopyranosyl units with } \\
\alpha-\text { galactopyranosyl units }\end{array}$ & 220,000 & mannose, galactose & {$[36,128]$} \\
\hline
\end{tabular}


Table 5 Immunomodulatory Polysaccharide Products: Composition and Structure (Continued)

\begin{tabular}{|c|c|c|c|c|c|}
\hline & $\begin{array}{l}\text { Extract } \\
\text { (partially- } \\
\text { hydrolyzed } \\
\text { guar gum) }\end{array}$ & NA & 20,000 & mannose, galactose & {$[50]$} \\
\hline Flammulina velutipes & Extract & NA & NA & glucose, mannose, galactose & {$[117]$} \\
\hline Flammulina velutipes (fruit body) & Extract & $\beta-1,3$ glucan & NA & glucose & [129] \\
\hline \multirow[t]{2}{*}{ Ganoderma lucidum } & Whole tissue & $\begin{array}{l}\text { Linear } \beta \text {-1,3-glucans with } \\
\text { varying degrees of } \\
\text { D-glucopyranosyl branching, } \\
\beta \text {-glucan/protein complexes, } \\
\text { heteropolysaccharides }\end{array}$ & $400,000-1,000,000$ & $\begin{array}{l}\text { glucose, galactose, mannose, } \\
\text { xylose, uronic acid }\end{array}$ & {$[130]$} \\
\hline & Extract & NA & $7,000-9,000$ & NA & {$[67]$} \\
\hline \multirow[t]{2}{*}{ Ganoderma lucidum (fruit body) } & Extract & NA & $7,000-9,000$ & NA & \\
\hline & & $\beta$-linked heteroglycan peptide & 513,000 & $\begin{array}{l}\text { fructose, galactose, glucose, } \\
\text { rhamnose, xylose (3.167: } \\
\text { 0.556:6.89:0.549:3.61) }\end{array}$ & {$[15]$} \\
\hline Ganoderma tsugae & Extract & $\begin{array}{l}55.6 \% \text { carbohydrates }(12.5 \% \\
\text { polysaccharides); } 12 \% \\
\text { triterpenes, } 1.7 \% \text { sodium, } 0.28 \% \\
\text { protein, } 0 \% \text { lipid }\end{array}$ & NA & NA & {$[53]$} \\
\hline Ginkgo biloba (seed) & Extract & $89.7 \%$ polysaccharides & NA & $\begin{array}{l}\text { glucose, fructose, galactose, } \\
\text { rhamnose }\end{array}$ & {$[131]$} \\
\hline Grifola frondosa & Whole tissue & $\begin{array}{l}\beta-1,3 ; 1,6 \text {-glucans, } \alpha \text {-glucans, } \\
\text { mannoxyloglucans, xyloglucans, } \\
\text { mannogalactofucans }\end{array}$ & NA & $\begin{array}{l}\text { glucose, fucose, xylose, } \\
\text { mannose, galactose }\end{array}$ & {$[117]$} \\
\hline \multirow[t]{2}{*}{ Grifola frondosa (fruit body) } & $\begin{array}{l}\text { Extract } \\
\text { (D fraction) }\end{array}$ & $\begin{array}{l}\beta \text {-1,6-glucan with } \beta-1,3 \\
\text { branches, } 30 \% \text { protein }\end{array}$ & NA & glucose & {$[132]$} \\
\hline & $\begin{array}{l}\text { Extract } \\
\text { (X fraction) }\end{array}$ & $\begin{array}{l}\beta \text {-1,6-D-glucan with } \alpha-1,4 \\
\text { branches, 35\% protein }\end{array}$ & $550,000-558,000$ & glucose & \\
\hline \multirow[t]{2}{*}{ Hordeum spp. (seed) } & Extract & $\beta$-1,3;1,4-and $\beta$-1,3;1,6-D-glucans & $45,000-404,000$ & glucose & [75] \\
\hline & & $\begin{array}{l}\text { Primarily linear } \beta-1,3 ; 1,4- \\
\text { glucans }\end{array}$ & NA & glucose & {$[124]$} \\
\hline \multirow{2}{*}{$\begin{array}{l}\text { Laminaria spp. } \\
\text { (frond) }\end{array}$} & & $\begin{array}{l}\beta-1,3 \text { glucan with some } \beta-1,6 \\
\text { branches and a small amount } \\
\text { of protein }\end{array}$ & $4,500-5,500$ & glucose & [44] \\
\hline & Extract & Fucoidan & NA & NA & {$[133]$} \\
\hline Larix occidentalis (bark) & Extract & $\begin{array}{l}\beta-1,3 ; 1,6-D-g a l a c t a n s \text { with } \\
\text { arabinofuranosyl and } \\
\text { arabinopyranosyl side chains }\end{array}$ & $19,000-40,000$ & $\begin{array}{l}\text { galactose:arabinose (6:1), } \\
\text { uronic acid }\end{array}$ & {$[128,134]$} \\
\hline \multirow[t]{4}{*}{ Lentinula edodes } & Extract (SME) & $\begin{array}{l}\beta-1,3-\text { glucans }(4-5 \%), \alpha-1,4- \\
\text { glucan (8-10\%), protein } \\
(11-14 \%)\end{array}$ & NA & glucose & {$[80]$} \\
\hline & Extract & $\beta$-glucan & 1,000 & glucose & {$[27]$} \\
\hline & Whole tissue & $\begin{array}{l}\text { Linear } \beta-1,3 \text {-glucans, } \beta-1,4 ; 1,6- \\
\text { glucans, heterogalactan }\end{array}$ & NA & $\begin{array}{l}\text { glucose, galactose, mannose, } \\
\text { fucose, xylose }\end{array}$ & {$[135]$} \\
\hline & $\begin{array}{l}\text { Extract } \\
\text { (lentinan) }\end{array}$ & $\begin{array}{l}\beta-1,3-\text { glucan with } 2 \beta-1,6 \\
\text { glucopyranoside branchings for } \\
\text { every } 5 \beta \text {-1,3-glucopyranoside } \\
\text { linear linkages }\end{array}$ & 500,000 & glucose & [136] \\
\hline \multirow[t]{2}{*}{$\begin{array}{l}\text { Lentinula edodes (fruit body) } \\
\text { Lentinula edodes }\end{array}$} & $\begin{array}{l}\text { Extract } \\
\text { (lentinan) }\end{array}$ & $\begin{array}{l}\text { Neutral } \beta-1,3-D \text { glucan with two } \\
\beta-1,6 \text { glucoside branches for } \\
\text { every five } \beta-1,3 \text { units }\end{array}$ & $400,000-800,000$ & glucose & {$[137]$} \\
\hline & $\begin{array}{l}\text { Extract } \\
\text { (KS-2) }\end{array}$ & $\begin{array}{l}\text { Peptide units and mannan } \\
\text { connected by } \alpha \text {-glycosidic } \\
\text { bonds }\end{array}$ & $60,000-90,000$ & mannose, glucose & \\
\hline
\end{tabular}


Table 5 Immunomodulatory Polysaccharide Products: Composition and Structure (Continued)

\begin{tabular}{|c|c|c|c|c|c|}
\hline $\begin{array}{l}\text { Lentinula edodes (mycelia or fruit } \\
\text { body) }\end{array}$ & Extract & $\begin{array}{l}\text { Triple helical } \beta-1,3-D \text { glucan } \\
\text { with } \beta-1,6 \text { glucoside branches }\end{array}$ & $1,000,000$ & glucose & {$[3]$} \\
\hline \multirow[t]{2}{*}{ Lentinula edodes (mycelia) } & $\begin{array}{l}\text { Extract } \\
\text { (LEM) }\end{array}$ & $44 \%$ sugars, $24.6 \%$ protein & $\sim 1,000,000$ & $\begin{array}{l}\text { xylose, arabinose, glucose, } \\
\text { galactose, mannose, fructose }\end{array}$ & {$[3]$} \\
\hline & $\begin{array}{l}\text { Extract } \\
(\text { PG101) }\end{array}$ & $\begin{array}{l}72.4 \% \text { polysaccharides, } 26.2 \% \\
\text { protein, } 1.4 \% \text { hexosamine }\end{array}$ & NA & $\begin{array}{l}55.6 \% \text { glucose, } 25.9 \% \\
\text { galactose, } 18.5 \% \text { mannose }\end{array}$ & {$[138]$} \\
\hline Lycium barbarum & Whole tissue & $\begin{array}{l}\alpha-1,4 ; 1,6-D-g l u c a n s, \text { lentinan, } \\
\beta-1,3 ; 1,6 \text { heteroglucans, } \\
\text { heterogalactans, } \\
\text { heteromannans, xyloglucans }\end{array}$ & NA & $\begin{array}{l}\text { glucose, galactose, mannose, } \\
\text { xylose }\end{array}$ & {$[139]$} \\
\hline Lycium barbarum (fruit body) & $\begin{array}{l}\text { Extract } \\
\left(\mathrm{LBP}_{3 \mathrm{p}}\right)\end{array}$ & $88.36 \%$ sugars, $7.63 \%$ protein & 157,000 & $\begin{array}{l}\text { galactose, glucose, } \\
\text { rhamnose, arabinose, } \\
\text { mannose, xylose (molar ratio } \\
\text { of } 1: 2.12: 1.25: 1.10: 1.95: 1.76 \text { ) }\end{array}$ & {$[91]$} \\
\hline \multirow[t]{3}{*}{ Panax quinquefolium (root) } & Extract & $\begin{array}{l}\text { Poly-furanosyl-pyranosyl } \\
\text { saccharides }\end{array}$ & NA & $\begin{array}{l}\text { arabinose, galactose, } \\
\text { rhamnose, galacturonic acid, } \\
\text { glucuronic acid }\end{array}$ & {$[33]$} \\
\hline & & NA & NA & glucose, mannose, xylose & {$[140]$} \\
\hline & $\begin{array}{l}\text { Extract } \\
\left(\text { Cold-f } X^{\circledR}\right)\end{array}$ & $\begin{array}{l}\text { 90\% poly-furanosyl-pyranosyl- } \\
\text { saccharides }\end{array}$ & NA & furanose & {$[20]$} \\
\hline Phellinus linteus (fruit body) & Extract & $\begin{array}{l}\alpha \text { - and } \beta \text {-linked } 1,3 \text { acidic } \\
\text { proteoglycan with } 1,6 \text { branches }\end{array}$ & 150,000 & $\begin{array}{l}\text { glucose, mannose, arabinose, } \\
\text { xylose }\end{array}$ & [141] \\
\hline Phellinus linteus (mycelia) & Extract & $\begin{array}{l}83.2 \% \text { polysaccharide }(4.4 \% \\
\beta \text {-glucan), } 6.4 \% \text { protein, } 0.1 \% \text { fat }\end{array}$ & NA & glucose & {$[142]$} \\
\hline Pholiota nameko (fruit body) & $\begin{array}{l}\text { Extract (PNPS- } \\
\text { 1) }\end{array}$ & NA & 114,000 & $\begin{array}{l}\text { mannose, glucose, galactose, } \\
\text { arabinose, xylose (molar ratio } \\
\text { of } 1: 8.4: 13.6: 29.6: 6.2 \text { ) }\end{array}$ & {$[55]$} \\
\hline Pleurotus ostreatus (mycelia) & Extract & $\beta$-1,3;1,6-D-glucans & 316,260 & glucose & {$[143]$} \\
\hline \multirow[t]{3}{*}{ Saccharomyces cerevisiae } & Extract (WGP) & Particulate $\beta$-1,3;1,6-D-glucan & NA & glucose & {$[144]$} \\
\hline & Extract & $\begin{array}{l}\beta \text {-glucans with } \beta-1,6 \text { branches } \\
\text { with a } \beta-1,3 \text { regions }\end{array}$ & NA & glucose & {$[124]$} \\
\hline & $\begin{array}{l}\text { Extract } \\
\text { (SBG) }\end{array}$ & $\begin{array}{l}\text { soluble } \beta-1,3-D-g l u c a n \text { with } \\
\beta-1,3 \text { side chains attached with } \\
\beta-1,6 \text { linkages }\end{array}$ & 20,000 & glucose & {$[145]$} \\
\hline Sclerotinia sclerotiorum (mycelia) & $\begin{array}{l}\text { Extract } \\
\text { (SSG) }\end{array}$ & $\begin{array}{l}\beta-1,3-D-g l u c a n,<1 \% \text { protein } \\
(>98 \% \text { polysaccharide) }\end{array}$ & NA & glucose & {$[83]$} \\
\hline Sclerotium rofsii & $\begin{array}{l}\text { Extract } \\
\text { (scleroglucan) }\end{array}$ & $\beta-1,3 ; 1,6$ glucan & $1,000,000$ & glucose & {$[29]$} \\
\hline Trametes versicolor (fruit body) & $\begin{array}{l}\text { Extract } \\
\text { (PSP) }\end{array}$ & $\begin{array}{l}\alpha-1,4, \beta-1,3 \text { glucans, } 10 \% \\
\text { peptides }\end{array}$ & 100,000 & $\begin{array}{l}\text { glucose, arabinose, mannose, } \\
\text { rhamnose }\end{array}$ & [146] \\
\hline Trametes versicolor (mycelia) & $\begin{array}{l}\text { Extract } \\
\text { (PSK) }\end{array}$ & $\beta-1,4 ; 1,3 ; 1,6-D-$ glucans, protein & 94,000 & $\begin{array}{l}\text { glucose }(74.6 \%), \text { mannose } \\
(15.5 \%), \text { xylose }(4.8 \%) \\
\text { galactose }(2.7 \%), \text { fucose } \\
(2.4 \%)\end{array}$ & {$[137,147]$} \\
\hline \multirow[t]{3}{*}{ Undaria pinnatifida (sporophyll) } & Extract & Galactofucan sulfate & 9,000 & fucose:galactose 1.0:1.1 & {$[148]$} \\
\hline & & Galactofucan sulfate & 63,000 & $\begin{array}{l}\text { fucose:galactose:gluc-uronic } \\
\text { acid (1.0:1.0:0.04) }\end{array}$ & {$[149]$} \\
\hline & & $\beta$-1,3-galactofucan sulphate & 38,000 & fucose, galactose & {$[150]$} \\
\hline \multirow[t]{2}{*}{ Unidentified source } & $\begin{array}{l}\text { Extract } \\
\text { (modified } \\
\text { citrus pectin) }\end{array}$ & NA & 10,000 & $\begin{array}{l}\text { galactose, rhamnose, uronic } \\
\text { acid }\end{array}$ & {$[125]$} \\
\hline & $\begin{array}{l}\text { Extract (highly } \\
\text { methoxylated } \\
\text { pectin) }\end{array}$ & NA & 200,000 & NA & {$[36]$} \\
\hline
\end{tabular}


Table 6 Safety of Immunomodulatory Polysaccharide Products Following Oral Intake

\begin{tabular}{|c|c|c|c|c|c|c|c|}
\hline Category & Source & Test group & Test & Design & Results & $\begin{array}{l}\text { Equivalent } \\
\text { human } \\
\text { dose* }\end{array}$ & Reference \\
\hline \multirow[t]{2}{*}{$\begin{array}{l}\text { Arabino- } \\
\text { galactans }\end{array}$} & $\begin{array}{l}\text { Argemone } \\
\text { mexicana } \\
\text { (arabinogalactan } \\
\text { protein) }\end{array}$ & Pregnant rats & $\begin{array}{l}\text { Develop- } \\
\text { mental } \\
\text { toxicity }\end{array}$ & $\begin{array}{l}250,500 \text {, or } 1,00 \\
\mathrm{mg} / \mathrm{kg}, \text { gestational } \\
\text { days } 5-19\end{array}$ & $\begin{array}{l}\text { No developmental toxicity: } \\
\text { NOAEL }=1 \mathrm{~g} / \mathrm{kg}\end{array}$ & $68 \mathrm{~g}$ & [151] \\
\hline & & $\Phi$ and $o^{n}$ rats & Fertility & $\begin{array}{l}250,500, \text { or } 1,00 \\
\mathrm{mg} / \mathrm{kg}, 1 \text { month }\end{array}$ & $\begin{array}{l}\text { No effects on reproduction: } \\
\text { NOAEL }=1 \mathrm{~g} / \mathrm{kg}\end{array}$ & & \\
\hline Fucoidans & $\begin{array}{l}\text { Undaria } \\
\text { pinnatifida }\end{array}$ & Rats & $\begin{array}{l}\text { Subchronic } \\
\text { toxicity }\end{array}$ & $\begin{array}{l}1.35 \mathrm{~g} / \mathrm{kg}, 1 \\
\text { month }\end{array}$ & No evidence of toxicity & $91.8 \mathrm{~g}$ & [152] \\
\hline \multirow[t]{10}{*}{$\begin{array}{l}\text { Galacto- } \\
\text { mannans }\end{array}$} & $\begin{array}{l}\text { Cyamopsis } \\
\text { tetragonolobus }\end{array}$ & $\begin{array}{l}\text { Adolescent and } \\
\text { adult ơ rats }\end{array}$ & $\begin{array}{l}\text { Subchronic } \\
\text { and chronic } \\
\text { toxicity }\end{array}$ & $\begin{array}{l}8 \% \text { of diet, } 6-67 \\
\text { weeks }\end{array}$ & No evidence of toxicity & $8 \%$ of diet & [153] \\
\hline & & Rats & $\begin{array}{l}\text { Acute } \\
\text { toxicity }\end{array}$ & $\begin{array}{l}\text { One } 7.06 \mathrm{~g} / \mathrm{kg} \\
\text { dose: observed } 2 \\
\text { weeks }\end{array}$ & $\mathrm{LD}_{50}=7.06 \mathrm{~g} / \mathrm{kg}$ & $480 \mathrm{~g}$ & [96] \\
\hline & & & $\begin{array}{l}\text { Subchronic } \\
\text { and chronic } \\
\text { toxicity }\end{array}$ & $\begin{array}{l}1,2,4,7.5 \text { or } 15 \% \\
\text { of diet, } 3 \text { months }\end{array}$ & $\begin{array}{l}\text { All doses } \downarrow \text { O BW; 7.5-15\% } \downarrow \text { O" } \\
\text { BW; } 15 \% \downarrow \text { bone marrow } \\
\text { cellularity; } \downarrow \text { kidney and liver } \\
\text { weights }\end{array}$ & $\begin{array}{l}1-15 \% \text { of } \\
\text { diet }\end{array}$ & \\
\hline & & $\begin{array}{l}19 \text { adults with } \\
\text { hypercholesterol- } \\
\text { emia }\end{array}$ & & 18 g/day, 1 year & $\begin{array}{l}\text { Short-term gastric bloating/loose } \\
\text { stools, in } 8 \text { subjects, resolved in } \\
7-10 \text { days; } 2 \text { withdrew because of } \\
\text { diarrhea. No toxicity for } 13 \\
\text { subjects completing study }\end{array}$ & $18 \mathrm{~g}$ & [154] \\
\hline & & $\begin{array}{l}16 \text { Type II } \\
\text { diabetics }\end{array}$ & & $\begin{array}{l}\text { 26.4-39.6 g/day, } 6 \\
\text { months }\end{array}$ & $\begin{array}{l}\text { No effects on hematologic, } \\
\text { hepatic, or renal function }\end{array}$ & $39.9 \mathrm{~g}$ & [155] \\
\hline & & $\begin{array}{l}18 \text { Type II } \\
\text { diabetics }\end{array}$ & & $\begin{array}{l}30 \mathrm{~g} / \text { day, } 4 \\
\text { months }\end{array}$ & & $30 \mathrm{~g}$ & \\
\hline & $\begin{array}{l}\text { Cyamopsis } \\
\text { tetragonolobus } \\
\text { (partially } \\
\text { hydrolyzed guar } \\
\text { gum) }\end{array}$ & Mice \& rats & $\begin{array}{l}\text { Acute } \\
\text { toxicity }\end{array}$ & $\begin{array}{l}\text { One } 6 \mathrm{~g} / \mathrm{kg} \text { dose; } \\
\text { observed } \\
2 \text { weeks }\end{array}$ & $\mathrm{LD}_{50}>6 \mathrm{~g} / \mathrm{kg}$ & $>408 \mathrm{~g}$ & {$[156]$} \\
\hline & & Rats & $\begin{array}{l}\text { Subchronic } \\
\text { toxicity }\end{array}$ & $\begin{array}{l}0.2,1.0 \text { or } 5 \% \text { of } \\
\text { diet, } 13 \text { weeks }\end{array}$ & No evidence of toxicity & $5 \%$ of diet & \\
\hline & & & & $\begin{array}{l}0.5 \text { or } 2.5 \mathrm{~g} / \mathrm{kg}, 1 \\
\text { month }\end{array}$ & NOAEL > $2.5 \mathrm{~g} / \mathrm{kg}$ & $>170 \mathrm{~g}$ & {$[157]$} \\
\hline & & S. typhimurium & Mutagenicity & Ames test & Not mutagenic & NA & \\
\hline \multirow[t]{5}{*}{ Glucans } & $\begin{array}{l}\text { Agaricus } \\
\text { subrufescens } \\
\text { (aqueous extract) }\end{array}$ & Rats & $\begin{array}{l}\text { Subchronic } \\
\text { toxicity }\end{array}$ & $\begin{array}{l}0.63,1.25,2.5 \text { or } \\
5 \% \text { of diet, } 3 \\
\text { months }\end{array}$ & NOAEL $=5 \%$ of diet & $5 \%$ of diet & [158] \\
\hline & & $\begin{array}{l}3 \text { women with } \\
\text { advanced } \\
\text { cancers }\end{array}$ & Case reports & $\begin{array}{l}\text { Specific identity of } \\
\text { products, doses, } \\
\text { and durations of } \\
\text { intake unknown }\end{array}$ & $\begin{array}{l}\text { Severe hepatotoxicity; two } \\
\text { patients died }\end{array}$ & NA & {$[97]$} \\
\hline & $\begin{array}{l}\text { Agaricus } \\
\text { subrufescens } \\
\text { (freeze dried } \\
\text { powder) }\end{array}$ & $\begin{array}{l}24 \text { normal adults } \\
\text { and } 24 \text { adults } \\
\text { with liver } \\
\text { problems }\end{array}$ & $\begin{array}{l}\text { Subchronic } \\
\text { toxicity }\end{array}$ & $3 \mathrm{~g}, 4$ months & No evidence of toxicity & $3 \mathrm{~g}$ & [159] \\
\hline & $\begin{array}{l}\text { Ganoderma } \\
\text { lucidum } \\
\text { (supplement) }\end{array}$ & Elderly woman & Case report & $\begin{array}{l}1 \text { year G. lucidum } \\
\text { (and another } \\
\text { unidentified } \\
\text { product, initiated } \\
\text { one month } \\
\text { previous) }\end{array}$ & $\begin{array}{l}\text { Elevated liver enzymes and liver } \\
\text { tissue damage }\end{array}$ & NA & [98] \\
\hline & $\begin{array}{l}\text { Grifola frondosa } \\
\text { (powder) }\end{array}$ & Rats & $\begin{array}{l}\text { Acute } \\
\text { toxicity }\end{array}$ & One $2 \mathrm{~g} / \mathrm{kg}$ dose & No evidence of toxicity & $136 \mathrm{~g}$ & [160] \\
\hline
\end{tabular}


Table 6 Safety of Immunomodulatory Polysaccharide Products Following Oral Intake (Continued)

\begin{tabular}{|c|c|c|c|c|c|c|c|}
\hline & $\begin{array}{l}\text { Lentinula edodes } \\
\text { (powder) }\end{array}$ & 10 adults & Safety & $\begin{array}{l}4 \mathrm{~g} / \text { day for } 10 \\
\text { weeks; repeated } \\
3-6 \text { months later }\end{array}$ & $\begin{array}{l}50 \% \text { of subjects experienced } \\
\text { blood eosinophilia, } \uparrow \text { eosinophil } \\
\text { granule proteins in serum and } \\
\text { stool, } \uparrow G \text { G symptoms }\end{array}$ & $4 \mathrm{~g}$ & {$[99]$} \\
\hline & \multirow[t]{2}{*}{$\begin{array}{l}\text { Lentinula edodes } \\
\text { (SME) }\end{array}$} & Nude mice & \multirow[t]{2}{*}{ Safety } & $\begin{array}{l}10 \% \text { of diet days } \\
1-18,33-50\end{array}$ & No adverse events & $10 \%$ of diet & \multirow[t]{2}{*}[80]{} \\
\hline & & $\begin{array}{l}61 \text { men with } \\
\text { prostate cancer }\end{array}$ & & $0.1 \mathrm{~g} / \mathrm{kg}, 6$ months & No adverse events & $6.8 \mathrm{~g}$ & \\
\hline & $\begin{array}{l}\text { Lentinus lepideus } \\
\text { (PG101) }\end{array}$ & Female mice & $\begin{array}{l}\text { Subchronic } \\
\text { toxicity }\end{array}$ & $0.5 \mathrm{~g} / \mathrm{kg}, 24$ days & No evidence of toxicity & $34 \mathrm{~g}$ & {$[92]$} \\
\hline & $\begin{array}{l}\text { Phellinus linteus } \\
\text { (crude extract) }\end{array}$ & Rats & $\begin{array}{l}\text { Acute } \\
\text { toxicity }\end{array}$ & $\begin{array}{l}\text { One } 5 \mathrm{~g} / \mathrm{kg} \text { dose; } \\
\text { observed } \\
2 \text { weeks }\end{array}$ & $\mathrm{LD}_{50}>5 \mathrm{~g} / \mathrm{kg}$ & $349 \mathrm{~g}$ & {$[161]$} \\
\hline & \multirow[t]{2}{*}{$\begin{array}{l}\text { Pleurotus } \\
\text { ostreatus } \\
\text { (aqueous extract) }\end{array}$} & \multirow[t]{2}{*}{ Mice } & $\begin{array}{l}\text { Acute } \\
\text { toxicity }\end{array}$ & $\begin{array}{l}\text { One } 3 \mathrm{~g} / \mathrm{kg} \text { dose; } \\
\text { observed } \\
1 \text { day }\end{array}$ & $\mathrm{LD}_{50}>3 \mathrm{~g} / \mathrm{kg}$ & $>204.9$ & \multirow[t]{2}{*}{ [100] } \\
\hline & & & $\begin{array}{l}\text { Subacute } \\
\text { toxicity }\end{array}$ & $\begin{array}{l}319 \mathrm{mg} / \mathrm{kg}, \\
1 \mathrm{month}\end{array}$ & $\begin{array}{l}\text { Hemorrhages in intestine, liver, } \\
\text { lung, kidney; inflammation and } \\
\text { microabscesses in liver }\end{array}$ & $21.7 \mathrm{~g}$ & \\
\hline & \multirow[t]{2}{*}{$\begin{array}{l}\text { Saccharomyces } \\
\text { cerevisiae } \\
\text { (particulate } \\
\text { glucan [WGP]) }\end{array}$} & \multirow[t]{2}{*}{ Rats } & $\begin{array}{l}\text { Acute } \\
\text { toxicity }\end{array}$ & $\begin{array}{l}\text { One } 2 \mathrm{~g} / \mathrm{kg} \text {, } \\
\text { observed } 2 \text { weeks }\end{array}$ & $\mathrm{LD}_{50}>2 \mathrm{~g} / \mathrm{kg}$ & $>136 \mathrm{~g}$ & \multirow[t]{2}{*}[144]{} \\
\hline & & & $\begin{array}{l}\text { Subchronic } \\
\text { toxicity }\end{array}$ & $\begin{array}{l}\text { 2, } 33.3 \text { or } 100 \text { mg/ } \\
\text { kg, } 3 \text { months }\end{array}$ & $\mathrm{NOAEL}=100 \mathrm{mg} / \mathrm{kg}$ & $6.80 \mathrm{~g}$ & \\
\hline \multirow[t]{4}{*}{ Heteroglycans } & $\begin{array}{l}\text { Trametes } \\
\text { versicolor } \\
\text { (PSP) }\end{array}$ & Rats & $\begin{array}{l}\text { Subchronic } \\
\text { toxicity }\end{array}$ & $\begin{array}{l}1.5,3.0 \text { or } 6.0 \mathrm{mg} / \\
\mathrm{kg}, 2 \text { months }\end{array}$ & No evidence of toxicity & $408 \mathrm{mg}$ & \multirow[t]{2}{*}[162]{} \\
\hline & & Rats \& monkeys & $\begin{array}{l}\text { Subchronic } \\
\text { and chronic } \\
\text { toxicity }\end{array}$ & $\begin{array}{l}\text { 100-200X } \\
\text { equivalent human } \\
\text { dose, } 6 \text { months }\end{array}$ & No evidence of toxicity & NA & \\
\hline & \multirow[t]{2}{*}{$\begin{array}{l}\text { Trametes } \\
\text { versicolor } \\
\text { (PSK) }\end{array}$} & $\begin{array}{l}\text { Humans with } \\
\text { colon cancer }\end{array}$ & \multirow[t]{2}{*}{ Safety } & $\begin{array}{l}3 \mathrm{~g} / \text { day, up to } \\
7 \text { years }\end{array}$ & \multirow[t]{2}{*}{ No significant adverse events } & $3 \mathrm{~g}$ & {$[57]$} \\
\hline & & $\begin{array}{l}\text { Humans with } \\
\text { colorectal cancer }\end{array}$ & & 3 g/day, 2 years & & $3 \mathrm{~g}$ & {$[58]$} \\
\hline \multirow[t]{2}{*}{ Mannans } & \multirow[t]{2}{*}{ Aloe vera gel } & Dogs & \multirow[t]{2}{*}{$\begin{array}{l}\text { Acute } \\
\text { toxicity }\end{array}$} & $\begin{array}{l}\text { Fed one } 32 \mathrm{~g} / \mathrm{kg} ; \\
\text { observed } 2 \text { weeks }\end{array}$ & LD50 > $32 \mathrm{~g} / \mathrm{kg}$ & $>2,176 \mathrm{~g}$ & \multirow[t]{2}{*}{$\begin{array}{l}\text { Bill Pine, } \\
\text { personal } \\
\text { communi- } \\
\text { cation }\end{array}$} \\
\hline & & Rats & & $\begin{array}{l}\text { One } 21.5 \mathrm{~g} / \mathrm{kg} ; \\
\text { observed } 2 \text { weeks }\end{array}$ & $\mathrm{LD} 50>10 \mathrm{~g} / \mathrm{kg}$ & $>680 \mathrm{~g}$ & \\
\hline
\end{tabular}

*150 lb adult

following intake of G. lucidum aqueous extracts; in one study intake was $5 \%$ of the diet for 5 months (Table 1). While adverse effects were also reported in a study in which 10 adults consumed $4 \mathrm{~g} /$ day $L$. edodes powder for 10 weeks [99], immunologic animal studies reported no ill effects of either $L$. edodes powder ( 5 studies, up to $5 \%$ of the diet up to nine months) or extract (7 studies, up to 40 days intake) (Tables 1 and 3). Finally, while intake of $319 \mathrm{mg} / \mathrm{kg}$ of an aqueous extract of $P$. ostreatus by mice for 1 month caused hemorrhages in multiple tissues [100], there was no reported toxicity when mice consumed the mushroom powder as $5 \%$ of their diet for nine months (Table 3). While $\geq 1$ gram/day of $T$. versicolor glucan products were safely consumed by cancer patients for up to 10 years, the long-term effects of ingestion of the other polysaccharide products discussed in this review is also not known.

\section{Discussion}

The majority of studies that qualified for inclusion in this review employed models investigating immune stimulation; fewer explored anti-inflammatory effects. Animal studies reported immune system effects in the gut, spleen, bone marrow, liver, blood, thymus, lungs, and saliva; controlled human studies reported evidence of immune stimulation in the blood, anti-inflammatory 
effects in nasal lavage fluid and improved survival in cancer patients. The literature is highly heterogenous and is not sufficient to support broad structure/function generalizations. For the limited number of studies that investigated well-characterized, isolated products (primarily glucan products), effects can be unequivocally attributed to polysaccharides. Such associations are certainly more tenuous when considering product powders or products obtained by extraction methods designed to isolate polysaccharides, but without complete compositional analyses.

Dietary polysaccharides are known to impact gut microbial ecology $[101,102]$, and advances in microbial ecology, immunology and metabolomics indicate that gut microbiota can impact host nutrition, immune modulation, resistance to pathogens, intestinal epithelial development and activity, and energy metabolism [103-107]. Other than fucoidans, the polysaccharides discussed in this review appear to be at least partially degraded by bacterial enzymes in the human digestive tract (Table 7). Arabinogalactans, galactomannans, a glucan (laminarin), glucomannans, and mixed polysaccharide products (Ambrotose ${ }^{\oplus}$ products) have been shown to be metabolized by human colonic bacteria. Orally ingested fucoidans, glucans and mannans (or their fragments) have been detected in numerous tissues and organs throughout the body $[73,108,109]$, (Carrington Laboratories, personal communication). We know of no study that has determined the specific identity of orally-ingested polysaccharide end products in animal or human tissues.

One can only speculate upon the mechanisms by which the polysaccharides discussed in this review influence immunologic function, particularly when one considers the exceedingly complex environment of the GI tract. It is possible that fragments of polysaccharides partially hydrolyzed by gut bacteria may either bind to gut epithelia and exert localized and/or systemic immune system effects, or be absorbed into the bloodstream, with the potential to exert systemic effects. Current studies investigating the link between the bioconversion of dietary polysaccharides, their bioavailability and their downstream effects on the host

Table 7 Fate of Immunomodulatory Polysaccharide Products Following Oral Intake

\begin{tabular}{|c|c|c|c|c|c|}
\hline Category & Product & $\begin{array}{l}\text { Metabol-ized } \\
\text { by human gut } \\
\text { bacteria? }\end{array}$ & $\begin{array}{l}\text { Study } \\
\text { type }\end{array}$ & $\begin{array}{l}\text { Fate } \\
\text { (method: tissues detected) }\end{array}$ & References \\
\hline Arabinogalactans & Larix spp. & yes & in vitro & NA & [163-169] \\
\hline Fucoidans & Undaria pinnatifida & no & in vitro & Ab: human plasma & {$[108,170]$} \\
\hline \multirow[t]{2}{*}{ Galactomannans } & $\begin{array}{l}\text { Cyamopsis tetragonolobus } \\
\text { (partially hydrolyzed guar gum) }\end{array}$ & yes & in vivo & NA & {$[171]$} \\
\hline & $\begin{array}{l}\text { Cyamopsis tetragonolobus (guar } \\
\text { gum) }\end{array}$ & yes & in vitro & NA & {$[167]$} \\
\hline \multirow[t]{5}{*}{ Glucans } & Hordeum vulgare & NA & in vivo & $\begin{array}{l}\text { Fluorescein-labeled: mouse Mø in the spleen, } \\
\text { bone marrow, lymph nodes }\end{array}$ & {$[73]$} \\
\hline & Laminaria digitata (laminarin) & yes & in vitro & NA & {$[29,170,172]$} \\
\hline & $\begin{array}{l}\text { Sclerotium rofsii (scleroglucan) } \\
\text { glucan phosphate, Laminaria } \\
\text { spp. (laminarin) }\end{array}$ & NA & in vivo & $\begin{array}{l}\text { Alexa Fluor 488-labeled: mouse intestinal } \\
\text { epithelial cells, plasma, GALT }\end{array}$ & {$[29]$} \\
\hline & $\begin{array}{l}\text { Saccharomyces cervisiae } \\
\text { (particulate) }\end{array}$ & NA & in vivo & $\begin{array}{l}\text { Fluorescein-labeled: mouse macrophage in } \\
\text { the spleen, bone marrow, lymph nodes }\end{array}$ & {$[73]$} \\
\hline & $\begin{array}{l}\text { Trametes versicolor } \\
\text { (PSK) }\end{array}$ & NA & in vivo & $\begin{array}{l}{ }^{14} \mathrm{C} \text {-labeled: rat and rabbit serum; mouse Gl } \\
\text { tract, bone marrow, salivary glands, liver, } \\
\text { brain, spleen, pancreas }\end{array}$ & {$[173]$} \\
\hline \multirow[t]{3}{*}{ Mannans } & Aloe barbadensis (aloemannan) & yes & in vitro & FITC-labeled: mouse, Gl tract & {$[121,174]$} \\
\hline & $\begin{array}{l}\text { Aloe barbadensis } \\
\text { (gel powder) }\end{array}$ & yes & in vitro & NA & {$[163]$} \\
\hline & Aloe barbadensis (acemannan) & NA & in vivo & $\begin{array}{l}{ }^{14} \text { C-labeled: dog systemic, particularly liver, } \\
\text { bone marrow, gut, kidney, thymus, spleen }\end{array}$ & $\begin{array}{l}\text { (Carrington } \\
\text { Laboratories, } \\
\text { personal } \\
\text { communication) }\end{array}$ \\
\hline $\begin{array}{l}\text { Mixed } \\
\text { polysaccharide } \\
\text { products }\end{array}$ & $\begin{array}{l}\text { Ambrotose complex }{ }^{\circledast} \\
\text { Advanced Ambrotose } \\
\text { Ad powder }^{\circledR}\end{array}$ & yes & in vitro & NA & {$[163,175]$} \\
\hline \multirow[t]{2}{*}{ Pectins } & NA & yes & in vitro & NA & {$[165-167,176]$} \\
\hline & $\begin{array}{l}\text { Buplerum falcatum (bupleuran } \\
\text { 2llc) }\end{array}$ & NA & in vivo & Ab bound: mouse Peyer's patch, liver & {$[109]$} \\
\hline
\end{tabular}


metabolism and physiology are utilizing metabolomic and metagenomic approaches that can detect and track diverse microbial metabolites from immunomodulatory polysaccharides [103]. These and other innovative approaches in the field of colonic fermentation are providing novel insights into gut microbial-human mutualism [110,111], its impact on regulating human health and disease, and the importance of dietary modulation [112-115].

Additional RCTs of well-characterized products are needed to more completely understand the immunomodulatory effects and specific applications of oral polysaccharides. Such studies will need to better investigate the optimal timing and duration for polysaccharide ingestion. That is, should they be consumed continuously, before, at the time of, or after exposure to a pathogen or environmental insult? Only a few studies have actually investigated the impact of timing of polysaccharide intake to achieve optimal benefits. Daily feeding with some polysaccharides appears to result in tolerance (and diminished benefits); this has been demonstrated for some mushroom $\beta$-glucans $[3,26]$. For those polysaccharides whose immunologic effects are dependent on their prebiotic activities, regular feeding would be presumed necessary.

\section{Conclusions}

The dietary polysaccharides included in this review have been shown to elicit diverse immunomodulatory effects in animal tissues, including the blood, GI tract, and spleen. In controlled human trials, polysaccharide intake stimulated the immune system in the blood of healthy adults, dampened the allergic response to a respiratory inflammatory agent, and improved survival in cancer patients. Additional RCTs of well-characterized products are needed to more completely understand the immunomodulatory effects and specific applications of oral polysaccharides

\section{List of abbreviations}

O: female; O': male; Ab: antibody; AIDS: autoimmune deficiency syndrome; AOM: azoxymethane; BBN: Nbutyl-N'-butanolnitrosamine; BLCL: Burkitt's Lymphoma Cell Line; BW: body weight; CBC: complete blood count; $\mathrm{CD}$ : cluster of differentiation; CFU: colony forming unit; ConA: concanavalin A; CXCR: CXC chemokine receptor; DMBA: 7,12-dimethylbenz(a) anthracene; DMH: N-N'-dimethylhydrazine; DMN: dimethylhydrazine; DSS: dextran sulfate sodium; EBV: Epstein-Barr virus; GALT: gut-associated lymphoid tissue; GI: gastrointestinal; $\mathrm{H}_{2} \mathrm{O}_{2}$ : hydrogen peroxide; HSV: herpes simplex virus; ICR: imprinting control region; ID: intradermal; IEL: intraepithelial lymphocytes; IFN- $\lambda$ : interferon gamma; IG: intragastric; IgA: immunoglobulin A; IgE: immunoglobulin E; IgG: immunoglobulin G; IgM: immunoglobulin M; IL: interleukin; IMC: invasive micropapillary carcinoma; IN: intranasally; IP: intraperitoneal; IV: intravenous; LPS: lipopolysaccharide; Mø: macrophage; mAb: monoclonal antibody; 3-MCA: methylcholanthrene; MLN: mesenteric lymph nodes; MM-46 carcinoma: mouse mammary carcinoma; MW: molecular weight; NK: natural killer; NOAEL: no observable adverse effect level; OVA: ovalbumin; PBL: peripheral blood leukocytes; PBMC: peripheral blood mononuclear cells; PHA: phytohaemagglutinin; PMA: phorbol 12-myristate 13-acetate; PML: polymorphonuclear lymphocyte; RCT: randomized, controlled trial; RNA: ribonucleic acid; SC: subcutaneous; SD rats: Sprague Dawley; TCR: T cell receptor; TLR: toll like receptor; TNF- $\alpha$ : tumor necrosis factor alpha; UC: ulcerative colitis; WT: wild type.

\section{Acknowledgements}

The authors would like to thank Barbara K. Kinsey, Ward Moore and Mrs. Jennifer Aponte for their assistance with the preparation of this manuscript, and Dr. Azita Alavi and Mrs. Christy Duncan for their editorial assistance.

\section{Authors' contributions}

JER and EDN conducted literature searches and wrote the manuscript. RAS provided technical guidance. All authors read and approved the final manuscript.

\section{Competing interests}

The authors are employees of the Research \& Development Department at Mannatech, Incorporated, which sells two of the polysaccharide products (Ambrotose ${ }^{\circledast}$ powder and Advanced Ambrotose ${ }^{\circledast}$ powder) discussed in this review.

Received: 6 May 2010 Accepted: 18 November 2010 Published: 18 November 2010

\section{References}

1. Paulsen BS: Plant polysaccharides with immunostimulatory activities. Curr Org Chem 2001, 5:939-950.

2. Yamada $\mathrm{H}$, Kiyohara $\mathrm{H}$ : Complement-activating polysaccharides from medicinal herbs. In Immunomodulatory Agents from Plants. Edited by: Wagner H Basel. Switzerland: Birkhauser Verlag; 1999:

3. Hobbs C: Medicinal Mushrooms: An Exploration of Tradition, Healing and Culture Summertown, Tenn: Botanica Press; 2003.

4. Kusaykin M, Bakunina I, Sova V, Ermakova S, Kuznetsova T, Besednova N, et al: Structure, biological activity, and enzymatic transformation of fucoidans from the brown seaweeds. Biotechnol J 2008, 3:904-915.

5. Aloes. The genus aloe Boca Raton, Fla.: CRC Press; 2003.

6. Anderson JW, Smith BM, Gustafson NJ: Health benefits and practical aspects of high-fiber diets. Am J Clin Nutr 1994, 59:1242S-1247S.

7. Weickert MO, Pfeiffer AF: Metabolic effects of dietary fiber consumption and prevention of diabetes. J Nutr 2008, 138:439-442.

8. Estruch R, Martinez-Gonzalez MA, Corella D, Basora-Gallisa J, RuizGutierrez V, Covas Ml, et al: Effects of dietary fibre intake on risk factors for cardiovascular disease in subjects at high risk. J Epidemiol Community Health 2009, 63:582-588.

9. Pelley RP, Strickland FM: Plants, polysaccharides, and the treatment and prevention of neoplasia. Crit Rev Oncog 2000, 11:189-225.

10. Lull C, Wichers HJ, Savelkoul HF: Antiinflammatory and immunomodulating properties of fungal metabolites. Mediators Inflamm 2005, 2005:63-80. 
11. Chan GC, Chan WK, Sze DM: The effects of beta-glucan on human immune and cancer cells. J Hematol Oncol 2009, 2:25.

12. Schepetkin IA, Quinn MT: Botanical polysaccharides: macrophage immunomodulation and therapeutic potential. Int Immunopharmacol 2006, 6:317-333

13. Ma Y, Hebert JR, Li W, Bertone-Johnson ER, Olendzki B, Pagoto SL, et al: Association between dietary fiber and markers of systemic inflammation in the Women's Health Initiative Observational Study. Nutrition 2008, 24:941-949.

14. Hua KF, Hsu HY, Chao LK, Chen ST, Yang WB, Hsu J, et al: Ganoderma lucidum polysaccharides enhance CD14 endocytosis of LPS and promote TLR4 signal transduction of cytokine expression. J Cell Physiol 2007, 212:537-550.

15. Ho YW, Yeung JSL, Chiu PKY, Tang WM, Lin ZB, Man RYK, et al: Ganoderma lucidum polysaccharide peptide reduced the production of proinflammatory cytokines in activated rheumatoid synovial fibroblast. Mol Cell Biochem 2007, 301:173-179.

16. Kim MH, Joo HG: Immunostimulatory effects of fucoidan on bone marrow-derived dendritic cells. Immunol Lett 2008, 115:138-143.

17. Boh B, Berovic M, Zhang J, Zhi-Bin L: Ganoderma lucidum and its pharmaceutically active compounds. Biotechnol Annu Rev 2007, 13:265-301.

18. Nantz MP, Parker AR, MCGill C, Percival SS: Evaluation of arabinogalactan's effect on human immunity. FASEB Journal 2001, 15(4):A633.

19. Udani JK, Singh BB, Barrett ML, Singh VJ: Immunomodulatory effects of a proprietary arabinogalactan extract: a randomized, double-blind, placebo-controlled, parallel group study. Presented at the 50th Annual American College of Nutrition Meeting, Resort Lake Buena Vista, Florida, October 1-4, 20092009.

20. McElhaney JE, Goel V, Toane B, Hooten J, Shan JJ: Efficacy of COLD-fX in the prevention of respiratory symptoms in community-dwelling adults: a randomized, double-blinded, placebo controlled trial. J Altern Complement Med 2006, 12:153-157.

21. Irhimeh MR, Fitton $J H$, Lowenthal RM: Fucoidan ingestion increases the expression of CXCR4 on human CD34+ cells. Exp Hematol 2007, 35:989-994.

22. Chan Y, Chang T, Chan CH, Yeh YC, Chen CW, Shieh B, et al: Immunomodulatory effects of Agaricus blazei Murill in Balb/cByJ mice. J Microbiol Immunol Infect 2007, 40:201-208.

23. Takimoto H, Wakita D, Kawaguchi K, Kumazawa Y: Potentiation of cytotoxic activity in naive and tumor-bearing mice by oral administration of hot-water extracts from Agaricus blazei fruiting bodies. Biol Pharm Bull 2004, 27:404-406.

24. Mizuno M, Morimoto M, Minato K, Tsuchida H: Polysaccharides from Agaricus blazei stimulate lymphocyte T-cell subsets in mice. Biosci Biotechnol Biochem 1998, 62:434-437.

25. Yuminamochi E, Koike T, Takeda K, Horiuchi I, Okumura K: Interleukin-12and interferon-gamma-mediated natural killer cell activation by Agaricus blazei Murill. Immunology 2007, 121:197-206.

26. Hanaue H, Tokuda Y, Machimura T, Kamijoh A, Kondo Y, Ogoshi K, et al: Effects of oral lentinan on T-cell subsets in peripheral venous blood. Clin Ther 1989, 11:614-622.

27. Vetvicka V, Vashishta A, Saraswat-Ohri S, Vetvickova J: Immunological effects of yeast- and mushroom-derived beta-glucans. J Med Food 2008, 11:615-622.

28. Tsukada C, Yokoyama H, Miyaji C, Ishimoto Y, Kawamura H, Abo T: Immunopotentiation of intraepithelial lymphocytes in the intestine by oral administrations of beta-glucan. Cell Immunol 2003, 221:1-5.

29. Rice PJ, Adams EL, Ozment-Skelton T, Gonzalez AJ, Goldman MP, Lockhard BE, et al: Oral delivery and gastrointestinal absorption of soluble glucans stimulate increased resistance to infectious challenge. J Pharmacol Exp Ther 2005, 314:1079-1086.

30. Suzuki I, Hashimoto K, Ohno N, Tanaka H, Yadomae T: Immunomodulation by orally administered beta-glucan in mice. Int J Immunopharmacol 1989, 11:761-769.

31. Lim BO, Yamada K, Cho BG, Jeon T, Hwang SG, Park T, et al: Comparative study on the modulation of $\mathrm{IgE}$ and cytokine production by Phellinus linteus grown on germinated brown rice, Phellinus linteus and germinated brown rice in murine splenocytes. Biosci Biotechnol Biochem 2004, 68:2391-2394.
32. Oh GS, Lee MS, Pae HO, Kwon J, Lee SS, Jeong JG, et al: Effects of oral administration of Phellinus linteus on the production of Th1- and Th2type cytokines in mice. Immunopharmacol Immunotoxicol 2006, 28:281-293.

33. Biondo PD, Goruk S, Ruth MR, O'Connell E, Field CJ: Effect of CVT-E002 (COLD-fX) versus a ginsenoside extract on systemic and gut-associated immune function. Int Immunopharmacol 2008, 8:1134-1142.

34. Lim BO, Lee SH, Park DK, Choue RW: Effect of dietary pectin on the production of immunoglobulins and cytokines by mesenteric lymph node lymphocytes in mouse colitis induced with dextran sulfate sodium. Biosci Biotechnol Biochem 2003, 67:1706-1712.

35. Sakurai MH, Matsumoto T, Kiyohara H, Yamada H: B-cell proliferation activity of pectic polysaccharide from a medicinal herb, the roots of Bupleurum falcatum L. and its structural requirement. Immunology 1999, 97:540-547.

36. Yamada K, Tokunaga Y, Ikeda A, Ohkura K, Kaku-Ohkura S, Mamiya S, et al: Effect of dietary fiber on the lipid metabolism and immune function of aged Sprague-Dawley rats. Biosci Biotechnol Biochem 2003, 67:429-433.

37. Murphy EA, Davis JM, Brown AS, Carmichael MD, Ghaffar A, Mayer EP: Oat beta-glucan effects on neutrophil respiratory burst activity following exercise. Med Sci Sports Exerc 2007, 39:639-644.

38. Davis JM, Murphy EA, Brown AS, Carmichael MD, Ghaffar A, Mayer EP: Effects of oat beta-glucan on innate immunity and infection after exercise stress. Med Sci Sports Exerc 2004, 36:1321-1327.

39. Murphy EA, Davis JM, Carmichael MD, Mayer EP, Ghaffar A: Benefits of oat beta-glucan and sucrose feedings on infection and macrophage antiviral resistance following exercise stress. Am J Physiol Regul Integr Comp Physiol 2009, 297:R1188-R1194.

40. Murphy EA, Davis JM, Brown AS, Carmichael MD, Carson JA, Van RN, et al: Benefits of oat beta-glucan on respiratory infection following exercise stress: role of lung macrophages. Am J Physiol Regul Integr Comp Physiol 2008, 294:R1593-R1599.

41. Davis JM, Murphy EA, Brown AS, Carmichael MD, Ghaffar A, Mayer EP: Effects of moderate exercise and oat beta-glucan on innate immune function and susceptibility to respiratory infection. Am J Physiol Regul Integr Comp Physiol 2004, 286:R366-R372.

42. Yun CH, Estrada A, Van Kessel A: Immunomodulatory effects of oat betaglucan administered intragastrically or parenterally on mice infected with Eimeria vermiformis. Microbiol Immunol 1998, 42:457-465.

43. Yun CH, Estrada A, Van KA, Park BC, Laarveld B: Beta-glucan, extracted from oat, enhances disease resistance against bacterial and parasitic infections. FEMS Immunol Med Microbiol 2003, 35:67-75.

44. Neyrinck AM, Mouson A, Delzenne NM: Dietary supplementation with laminarin, a fermentable marine beta (1-3) glucan, protects against hepatotoxicity induced by LPS in rat by modulating immune response in the hepatic tissue. Int Immunopharmacol 2007, 7:1497-1506.

45. Hayashi K, Nakano T, Hashimoto M, Kanekiyo K, Hayashi T: Defensive effects of a fucoidan from brown alga Undaria pinnatifida against herpes simplex virus infection. Int Immunopharmacol 2008, 8:109-116.

46. Bernardshaw $S$, Hetland G, Grinde B, Johnson E: An extract of the mushroom Agaricus blazei Murill protects against lethal septicemia in a mouse model of fecal peritonitis. Shock 2006, 25:420-425.

47. Kirmaz C, Bayrak P, Yilmaz O, Yuksel H: Effects of glucan treatment on the Th1/Th2 balance in patients with allergic rhinitis: a double-blind placebo-controlled study. Eur Cytokine Netw 2005, 16:128-134.

48. Koray M, Ak G, Kurklu E, Tanyeri H, Aydin F, Oguz FS, et al: The effect of beta-glucan on recurrent aphthous stomatitis. J Altern Complement Med 2009, 15:111-113.

49. Matsumoto S, Nagaoka M, Hara T, Kimura-Takagi I, Mistuyama K, Ueyama S: Fucoidan derived from Cladosiphon okamuranus Tokida ameliorates murine chronic colitis through the down-regulation of interleukin-6 production on colonic epithelial cells. Clin Exp Immunol 2004, 136:432-439.

50. Naito Y, Takagi T, Katada K, Uchiyama K, Kuroda M, Kokura S, et al: Partially hydrolyzed guar gum down-regulates colonic inflammatory response in dextran sulfate sodium-induced colitis in mice. J Nutr Biochem 2006, 17:402-409.

51. Lim BO, Lee SH, Park DK, Choue RW: Effect of dietary pectin on the production of immunoglobulins and cytokines by mesenteric lymph node lymphocytes in mouse colitis induced with dextran sulfate sodium. Biosci Biotechnol Biochem 2003, 67:1706-1712. 
52. Koetzner L, Grover G, Boulet J, Jacoby H: Plant-derived polysaccharide dietary supplements inhibits dextran sulfate sodium-induced colitis in the rat. Dig Dis Sci 2010, 55:1278-1285.

53. Lin JY, Chen ML, Lin BF: Ganoderma tsugae in vivo modulates Th1/Th2 and macrophage responses in an allergic murine model. Food Chem Toxicol 2006, 44:2025-2032.

54. Lee JC, Pak SC, Lee SH, Na CS, Lim SC, Song CH, et al: Asian pear pectin administration during presensitization inhibits allergic response to ovalbumin in BALB/c mice. J Altern Complement Med 2004, 10:527-534.

55. Li H, Lu X, Zhang S, Lu M, Liu H: Anti-inflammatory activity of polysaccharide from Pholiota nameko. Biochemistry (Mosc) 2008, 73:669-675.

56. Mitomi T, Tsuchiya S, lijima N, Aso K, Suzuki K, Nishiyama K, et al: Randomized, controlled study on adjuvant immunochemotherapy with PSK in curatively resected colorectal cancer. The Cooperative Study Group of Surgical Adjuvant Immunochemotherapy for Cancer of Colon and Rectum (Kanagawa). Dis Colon Rectum 1992, 35:123-130.

57. Ito K, Nakazato H, Koike A, Takagi H, Saji S, Baba S, et al: Long-term effect of 5 -fluorouracil enhanced by intermittent administration of polysaccharide $\mathrm{K}$ after curative resection of colon cancer. $\mathrm{A}$ randomized controlled trial for 7-year follow-up. Int J Colorectal Dis 2004, 19:157-164.

58. Ohwada S, Ikeya T, Yokomori T, Kusaba T, Roppongi T, Takahashi T, et al: Adjuvant immunochemotherapy with oral Tegafur/Uracil plus PSK in patients with stage II or III colorectal cancer: a randomised controlled study. Br J Cancer 2004, 90:1003-1010.

59. Nakazato H, Koike A, Saji S, Ogawa N, Sakamoto J: Efficacy of immunochemotherapy as adjuvant treatment after curative resection of gastric cancer. Study Group of Immunochemotherapy with PSK for Gastric Cancer. Lancet 1994, 343:1122-1126.

60. Tsujitani S, Kakeji Y, Orita H, Watanabe A, Kohnoe S, Baba H, et al: Postoperative adjuvant immunochemotherapy and infiltration of dendritic cells for patients with advanced gastric cancer. Anticancer Res 1992, 12:645-648.

61. Torisu M, Hayashi Y, Ishimitsu T, Fujimura T, Iwasaki K, Katano M, et al: Significant prolongation of disease-free period gained by oral polysaccharide K (PSK) administration after curative surgical operation of colorectal cancer. Cancer Immunol Immunother 1990, 31:261-268.

62. Nio Y, Tsubono M, Tseng CC, Morimoto H, Kawabata K, Masai Y, et al: Immunomodulation by orally administered protein-bound polysaccharide PSK in patients with gastrointestinal cancer. Biotherapy 1992, 4:117-128.

63. Tsang KW, Lam CL, Yan C, Mak JC, Ooi GC, Ho JC, et al: Coriolus versicolor polysaccharide peptide slows progression of advanced non-small cell lung cancer. Respir Med 2003, 97:618-624.

64. Ahn WS, Kim DJ, Chae GT, Lee JM, Bae SM, Sin Jl, et al: Natural killer cell activity and quality of life were improved by consumption of a mushroom extract, Agaricus blazei Murill Kyowa, in gynecological cancer patients undergoing chemotherapy. Int J Gynecol Cancer 2004, 14:589-594.

65. Murakawa K, Fukunaga K, Tanouchi M, Hosokawa M, Hossain Z, Takahashi K. Therapy of myeloma in vivo using marine phospholipid in combination with Agaricus blazei Murill as an immune respond activator. J Oleo Sci 2007, 56:179-188.

66. Kobayashi H, Yoshida R, Kanada Y, Fukuda Y, Yagyu T, Inagaki K, et al: Suppressing effects of daily oral supplementation of beta-glucan extracted from Agaricus blazei Murill on spontaneous and peritoneal disseminated metastasis in mouse model. J Cancer Res Clin Oncol 2005, 131:527-538

67. Zhang Q-H, Lin Z-B: The antitumor activity of Ganoderma lucidum (Curt: Fr.) P. Karst. (LingZhi) (Aphyllophoromycetidease) polysaccharides is related to tumor necrosis factor-alpha and interferon-gamma. Int J Medicinal Mushrooms 1999, 207-215.

68. Lu H, Kyo E, Uesaka T, Katoh O, Watanabe H: A water-soluble extract from cultured medium of Ganoderma lucidum (Rei-shi) mycelia suppresses azoxymethane-induction of colon cancers in male F344 rats. Oncol Rep 2003, 10:375-379.

69. Lu H, Kyo E, Uesaka T, Katoh O, Watanabe H: Prevention of development of $\mathrm{N}_{\mathrm{N}} \mathrm{N}^{\prime}$-dimethylhydrazine-induced colon tumors by a water-soluble extract from cultured medium of Ganoderma lucidum (Rei-shi) mycelia in male ICR mice. Int J Mol Med 2002, 9:113-117.

70. Kurashige S, Akuzawa Y, Endo F: Effects of Lentinus edodes, Grifola frondosa and Pleurotus ostreatus administration on cancer outbreak, and activities of macrophages and lymphocytes in mice treated with a carcinogen, N-butyl-N-butanolnitrosoamine. Immunopharmacol Immunotoxicol 1997, 19:175-183.

71. Hishida I, Nanba H, Kuroda H: Antitumor activity exhibited by orally administered extract from fruit body of Grifola frondosa (maitake). Chem Pharm Bull (Tokyo) 1988, 36:1819-1827.

72. Nanba H, Kubo K: Effect of Maitake D-fraction on cancer prevention. Ann N Y Acad Sci 1997, 833:204-207.

73. Hong F, Yan J, Baran JT, Allendorf DJ, Hansen RD, Ostroff GR, et al: Mechanism by which orally administered (beta)-1,3-glucans enhance the tumoricidal activity of antitumor monoclonal antibodies in murine tumor models. J Immunol 2004, 173:797-806.

74. Modak S, Koehne G, Vickers A, O'Reilly RJ, Cheung NK: Rituximab therapy of lymphoma is enhanced by orally administered (1->3),(1->4)-D-betaglucan. Leuk Res 2005, 29:679-683.

75. Cheung NK, Modak S, Vickers A, Knuckles B: Orally administered betaglucans enhance anti-tumor effects of monoclonal antibodies. Cancer Immunol Immunother 2002, 51:557-564.

76. Cheung NK, Modak S: Oral (1->3),(1->4)-beta-D-glucan synergizes with antiganglioside GD2 monoclonal antibody 3F8 in the therapy of neuroblastoma. Clin Cancer Res 2002, 8:1217-1223.

77. Teas J, Harbison ML, Gelman RS: Dietary seaweed (Laminaria) and mammary carcinogenesis in rats. Cancer Res 1984, 44:2758-2761.

78. Nanba H, Mori K, Toyomasu T, Kuroda H: Antitumor action of shiitake (Lentinus edodes) fruit bodies orally administered to mice. Chem Pharm Bull (Tokyo) 1987, 35:2453-2458.

79. Sugui MM, ves de Lima PL, Delmanto RD, da Eira AF, Salvadori DM, Ribeiro LR: Antimutagenic effect of Lentinula edodes (BERK.) Pegler mushroom and possible variation among lineages. Food Chem Toxicol 2003, 41:555-560.

80. deVere White RW, Hackman RM, Soares SE, Beckett LA, Sun B: Effects of a mushroom mycelium extract on the treatment of prostate cancer. Urology 2002, 60:640-644.

81. Yap AT, Ng M-L: Immunopotentiating properties of lentinan (1-3)-b-Dglucan extracted from culinary-medicinal Shiitake mushroom. Int J Medicinal Mushrooms 2003, 5:19-39.

82. Ng ML, Yap AT: Inhibition of human colon carcinoma development by lentinan from shiitake mushrooms (Lentinus edodes). J Altern Complement Med 2002, 8:581-589.

83. Suzuki I, Sakurai T, Hashimoto K: Inhibition of experimental pulmonary metastasis of Lewis lung carcinoma by orally administered beta-glucan in mice. Chem Pharm Bull (Tokyo) 1991, 39:1606-1608.

84. Fujii T, Maeda H, Suzuki F, Ishida N: Isolation and characterization of a new antitumor polysaccharide, KS-2, extracted from culture mycelia of Lentinus edodes. J Antibiot (Tokyo) 1978, 31:1079-1090.

85. Ohkami H, Tazawa K, Yamashita I: Effects of apple pectin on fecal bacterial enzymes in azoxymethane- induced rat colon carcinogenesis. Jpn J Cancer Res 1995, 86:523-529.

86. Watanabe K, Reddy BS, Weisburger JH, Kritchevsky D: Effect of dietary alfalfa, pectin, and wheat bran on azoxymethane- or methylnitrosoureainduced colon carcinogenesis in F344 rats. J Natl Cancer Inst 1979, 63:141-145.

87. Hayashi A, Gillen AC, Lott JR: Effects of daily oral administration of quercetin chalcone and modified citrus pectin on implanted colon-25 tumor growth in Balb-c mice. Altern Med Rev 2000, 5:546-552.

88. Pienta KJ, Naik H, Akhtar A: Inhibition of spontaneous metastasis in a rat prostate cancer model by oral administration of modified citrus pectin. $J$ Natl Cancer Inst 1995, 87:348-353.

89. Nangia-Makker P, Hogan V, Honjo Y, Baccarini S, Tait L, Bresalier R, et al: Inhibition of human cancer cell growth and metastasis in nude mice by oral intake of modified citrus pectin. J Natl Cancer Inst 2002, 94:1854-1862.

90. Tazawa K, Okami H, Yamashita I: Anticarcinogenic action of apple pectin on fecal enzyme activities and mucosal or portal prostaglandin E2 levels in experimental rat colon carcinogenesis. J Exp Clin Cancer Res 1997, 16:33-38.

91. Gan L, Hua ZS, Liang Y, Bi XH: Immunomodulation and antitumor activity by a polysaccharide-protein complex from Lycium barbarum. Int Immunopharmacol 2004, 4:563-569.

92. Jin M, Jeon H, Jung HJ, Kim B, Shin SS, Choi JJ, et al: Enhancement of repopulation and hematopoiesis of bone marrow cells in irradiated mice 
by oral administration of PG101, a water-soluble extract from Lentinus lepideus. Exp Biol Med (Maywood) 2003, 228:759-766.

93. Ito $H$, Shimura $K$, Itoh $H$, Kawade M: Antitumor effects of a new polysaccharide-protein complex (ATOM) prepared from Agaricus blazei (Iwade strain 101) Himematsutake and its mechanisms in tumor-bearing mice. Anticancer Res 1997, 17:277-284.

94. Ho JC, Konerding MA, Gaumann A, Groth M, Liu WK: Fungal polysaccharopeptide inhibits tumor angiogenesis and tumor growth in mice. Life Sci 2004, 75:1343-1356.

95. Vinson JA, Al Kharrat $H$, Andreoli L: Effect of Aloe vera preparations on the human bioavailability of vitamins C and E. Phytomedicine 2005, 12:760-765.

96. Graham SL, Arnold A, Kasza L, Ruffin GE, Jackson RC, Watkins TL, et al: Subchronic effects of guar gum in rats. Food Cosmet Toxicol 1981, 19:287-290.

97. Mukai $\mathrm{H}$, Watanabe $\mathrm{T}$, Ando M, Katsumata $\mathrm{N}$ : An alternative medicine, Agaricus blazei, may have induced severe hepatic dysfunction in cancer patients. Jpn J Clin Oncol 2006, 36:808-810.

98. Yuen MF, Ip P, Ng WK, Lai CL: Hepatotoxicity due to a formulation of Ganoderma lucidum (lingzhi). J Hepatol 2004, 41:686-687.

99. Levy AM, Kita H, Phillips SF, Schkade PA, Dyer PD, Gleich GJ, et al: Eosinophilia and gastrointestinal symptoms after ingestion of shiitake mushrooms. J Allergy Clin Immunol 1998, 101:613-620.

100. Al Deen IH, Twaij HA, Al Badr AA, Istarabadi TA: Toxicologic and histopathologic studies of Pleurotus ostreatus mushroom in mice. $J$ Ethnopharmacol 1987, 21:297-305.

101. Flint HJ, Duncan SH, Scott KP, Louis P: Interactions and competition within the microbial community of the human colon: links between diet and health. Environ Microbiol 2007, 9:1101-1111.

102. Macfarlane GT, Steed H, Macfarlane S: Bacterial metabolism and healthrelated effects of galacto-oligosaccharides and other prebiotics. J App/ Microbiol 2008, 104:305-344.

103. Jacobs DM, Gaudier E, van DJ, Vaughan EE: Non-digestible food ingredients, colonic microbiota and the impact on gut health and immunity: a role for metabolomics. Curr Drug Metab 2009, 10:41-54.

104. Ishizuka S, Tanaka S, Xu H, Hara H: Fermentable dietary fiber potentiates the localization of immune cells in the rat large intestinal crypts. Exp Biol Med (Maywood) 2004, 229:876-884.

105. Garrett WS, Gordon Jl, Glimcher LH: Homeostasis and inflammation in the intestine. Cell 2010, 140:859-870.

106. Segain JP, Raingeard de la BD, Bourreille A, Leray V, Gervois N, Rosales C, et al: Butyrate inhibits inflammatory responses through NFkappaB inhibition: implications for Crohn's disease. Gut 2000, 47:397-403.

107. Mazmanian SK, Kasper DL: The love-hate relationship between bacterial polysaccharides and the host immune system. Nat Rev Immunol 2006, 6:849-858.

108. Irhimeh MR, Fitton JH, Lowenthal RM, Kongtawelert P: A quantitative method to detect fucoidan in human plasma using a novel antibody. Methods Find Exp Clin Pharmacol 2005, 27:705-710.

109. Sakurai MH, Matsumoto T, Kiyohara H, Yamada H: Detection and tissue distribution of anti-ulcer pectic polysaccharides from Bupleurum falcatum by polyclonal antibody. Planta Med 1996, 62:341-346.

110. Arasaradnam RP, Pharaoh MW, Williams GJ, Nwokolo CU, Bardhan KD, Kumar S: Colonic fermentation-more than meets the nose. Med Hypotheses 2009, 73:753-756.

111. Possemiers S, Grootaert C, Vermeiren J, Gross G, Marzorati M, Verstraete W et al: The intestinal environment in health and disease - recent insights on the potential of intestinal bacteria to influence human health. Curr Pharm Des 2009, 15:2051-2065.

112. Liu J, Gunn L, Hansen R, Yan J: Yeast-derived beta-glucan in combination with anti-tumor monoclonal antibody therapy in cancer. Recent Pat Anticancer Drug Discov 2009, 4:101-109.

113. Tuohy KM, Gougoulias C, Shen Q, Walton G, Fava F, Ramnani P: Studying the human gut microbiota in the trans-omics era-focus on metagenomics and metabonomics. Curr Pharm Des 2009, 15:1415-1427.

114. Schiffrin EJ, Morley JE, Donnet-Hughes A, Guigoz Y: The inflammatory status of the elderly: The intestinal contribution. Mutat Res 2010, 690:50-56.

115. Leung MY, Liu C, Koon JC, Fung KP: Polysaccharide biological response modifiers. Immunol Lett 2006, 105:101-114.
116. Noda H, Amano H, Arashima K, Hashimoto S, Nisizawa K: Antitumor activity of polysaccharides and lipids from marine algae. Nippon Suisan Gakkaishi 1989, 5:1265-1271.

117. Wasser SP: Medicinal mushrooms as a source of antitumor and immunomodulating polysaccharides. Appl Microbiol Biotechnol 2002, 60:258-274.

118. Firenzuoli F, Gori L, Lombardo G: The medicinal mushroom Agaricus blazei Murrill: Review of literature and pharmaco-toxicological problems. Evid Based Complement Alternat Med 2008, 5:3-15.

119. Luta G, McAnalley B: Aloe vera: chemical composition and methods used to determine its presence in commercial products. Glycoscience \& Nutrition 2005, 6:1-12.

120. Qiu Z, Jones K, Wylie M, Jia Q, Orndorff S: Modified Aloe barbadensis polysaccharide with immunoregulatory activity. Planta Med 2000, 66:152-156.

121. Yagi A, Nakamori J, Yamada T, Iwase H, Tanaka T, Kaneo Y, et al: In vivo metabolism of aloe mannan. Planta Med 1999, 65:417-420.

122. Pugh N, Ross SA, ElSohly MA, Pasco DS: Characterization of Aloeride, a new high-molecular-weight polysaccharide from Aloe vera with potent immunostimulatory activity. J Agric Food Chem 2001, 49:1030-1034.

123. Final report on the safety assessment of Aloe andongensis extract, Aloe andongensis leaf juice, Aloe arborescens leaf extract, Aloe arborescens leaf juice, Aloe arborescens leaf protoplasts, Aloe barbadensis flower extract, Aloe barbadensis leaf, Aloe barbadensis leaf extract, Aloe barbadensis leaf juice, Aloe barbadensis leaf polysaccharides, Aloe barbadensis leaf water, Aloe ferox leaf extract, Aloe ferox leaf juice, and Aloe ferox leaf juice extract. Int J Toxicol 2007, 26(Suppl 2):1-50

124. Akramiene D, Kondrotas A, Didziapetriene J, Kevelaitis E: Effects of betaglucans on the immune system. Medicina (Kaunas) 2007, 43:597-606.

125. Kidd PM: A new approach to metastatic cancer prevention: modified citrus pectin (MCP), a unique pectin that blocks cell surface lectins. Alt Med Rev 1996, 1:4-10.

126. Nagaoka M, Shibata H, Kimura-Takagi I, Hashimoto S, Kimura K, Makino T, et al: Structural study of fucoidan from Cladosiphon okamuranus TOKIDA. Glycoconj J 1999, 16:19-26.

127. Akaki J, Matsui Y, Kojima H, Nakajima S, Kamei K, Tamesada M: Structural analysis of monocyte activation constituents in cultured mycelia of Cordyceps sinensis. Fitoterapia 2009, 80:182-187.

128. Whistler RL, BeMiller JN: Carbohydrate Chemistry for Food Scientists. 2 edition. St. Paul, Minn.: American Association of Cereal Chemists, Inc; 1999.

129. Ohkuma T, Otagiri K, Ikekawa T, Tanaka S: Augmentation of antitumor activity by combined cryo-destruction of sarcoma 180 and proteinbound polysaccharide, EA6, isolated from Flammulina velutipes (Curt. ex Fr.) Sing. in ICR mice. J Pharmacobiodyn 1982, 5:439-444.

130. Wasser SP: Reishi or Ling Zhi (Ganoderma lucidum). In Encyclopedia of Dietary Supplements. Edited by: Coates PM, Blackman MR, Cragg GM, Levine M, Moss J, White JD. New York, New York: Marcel Dekker; 2005:603-622.

131. Song $G, X u A$, Chen $H$, Wang $X$ : Component analysis on polysaccharides in exocarp of Ginkgo biloba. Zhong Yao Cai 1997, 20:461-463.

132. Kubo K, Nanba H, Kuroda H: Modification of cellullar immune responses in experimental autoimmune hepatitis in mice by maitake (Grifola frondosa). Mycoscience 1998, 39:351-360

133. Berteau O, Mulloy B: Sulfated fucans, fresh perspectives: structures, functions, and biological properties of sulfated fucans and an overview of enzymes active toward this class of polysaccharide. Glycobiology 2003, 13:29R-40R.

134. D'Adamo P: Larch arabinogalactan. J Neuropath Med 1990, 6:33-37.

135. Chihara G, Maeda Y, Hamuro J, Sasaki T, Fukuoka F: Inhibition of mouse sarcoma 180 by polysaccharides from Lentinus edodes (Berk.) sing. Nature 1969, 222:687-688.

136. Chihara G: The antitumor polysaccharide Lentinan: an overview. In Manipulation of Host Defence Mechanisms. Edited by: Aoki T, Ichiro U, Eiro T. Excerpta Medica; 1981:1-16.

137. Trnovec T, Hrmova M: Immunomodulatory polysaccharides: chemistry, disposition and metabolism. Biopharm Drug Dispos 1993, 14:187-198.

138. Jin M, Jung HJ, Choi JJ, Jeon H, Oh JH, Kim B, et al: Activation of selective transcription factors and cytokines by water-soluble extract from Lentinus lepideus. Experimental Biology and Medicine 2003, 228:749-758.

139. Wasser SP: Shiitake (Lentinus edodes). In Encyclopedia of Dietary Supplements. Edited by: Coates PM, Blackman MR, Cragg GM, Levine M, Moss J, White JD. New York, New York: Marcell Dekker; 2005:653-664. 
140. Oshima $Y$, Sato $K$, Hikino H: Isolation and hypoglycemic activity of quinquefolans $A, B$, and $C$, glycans of Panax quinquefolium roots. J Nat Prod 1987, 50:188-190.

141. Zhu T, Kim SH, Chen CY: A medicinal mushroom: Phellinus linteus. Curr Med Chem 2008, 15:1330-1335.

142. Matsuba S, Matsuno H, Sakuma M, Komatsu Y: Phellinus linteus extract augments the immune response in mitomycin $\mathrm{C}$-induced immunodeficient mice. Evid Based Complement Alternat Med 2008, 5:85-90.

143. Refaie FM, Esmat AY, Daba AS, Taha SM: Characterization of polysaccharopeptides from Pleurotus ostreatus mycelium: assessment of toxicity and immunomodulation in vivo. Micologia Aplicada International 2009, 21:67-75.

144. Babicek K, Cechova I, Simon RR, Harwood M, Cox DJ: Toxicological assessment of a particulate yeast $(1,3 / 1,6)$-beta-D-glucan in rats. Food Chem Toxicol 2007, 45:1719-1730.

145. Lehne G, Haneberg B, Gaustad P, Johansen PW, Preus H, Abrahamsen TG: Oral administration of a new soluble branched beta-1,3-D-glucan is well tolerated and can lead to increased salivary concentrations of immunoglobulin A in healthy volunteers. Clin Exp Immunol 2006, 143:65-69.

146. Ng TB: A review of research on the protein-bound polysaccharide (polysaccharopeptide, PSP) from the mushroom Coriolus versicolor (Basidiomycetes: Polyporaceae). Gen Pharmacol 1998, 30:1-4.

147. Tsukagoshi S, Hashimoto Y, Fujii G, Kobayashi H, Nomoto K, Orita K: Krestin (PSK). Cancer Treat Rev 1984, 11:131-155.

148. Lee JB, Hayashi K, Hashimoto M, Nakano T, Hayashi T: Novel antiviral fucoidan from sporophyll of Undaria pinnatifida (Mekabu). Chem Pharm Bull (Tokyo) 2004, 52:1091-1094.

149. Katsube T, Yamasaki Y, Iwamoto M, Oka S: Hyaluronidase-inhibiting polysaccharide isolated and purified from hot water extract of sporophyll of Undaria pinnatifida. Food Sci Technol 2003, 9:25-29.

150. Koo JG, Jo KS, Do JR, Woo SJ: Isolation and purification of fucoidans from Laminara religiosa and Undaria pinnatifida in korea. J Korean Fish Soc 1995, 28:227-236.

151. Tamboli S, Arora S, Bhatnagar U, Vishwase G, Singh M: Reproductive and developmental toxicity evaluation of a purified Arabinogalactan-Protein (AGP) composition in Wistar rats. Fitoterapia 2010, 81:276-283.

152. Kim KJ, Lee $\mathrm{OH}$, Lee HH, Lee BY: A 4-week repeated oral dose toxicity study of fucoidan from the Sporophyll of Undaria pinnatifida in Sprague-Dawley rats. Toxicology 2010, 267:154-158.

153. Track NS, Cawkwell ME, Chin BC, Chiu SS, Haberer SA, Honey CR: Guar gum consumption in adolescent and adult rats: short- and long-term metabolic effects. Can J Physiol Pharmacol 1985, 63:1113-1121.

154. Simons LA, Gayst S, Balasubramaniam S, Ruys J: Long-term treatment of hypercholesterolaemia with a new palatable formulation of guar gum. Atherosclerosis 1982, 45:101-108.

155. Mclvor ME, Cummings CC, Van Duyn MA, Leo TA, Margolis S, Behall KM, et al: Long-term effects of guar gum on blood lipids. Atherosclerosis 1986, 60:7-13

156. Koujitani T, Oishi H, Kubo Y, Maeda T, Sekiya K, Yasuba M, et al: Absence of detectable toxicity in rats fed partially hydrolyzed guarm gum (K-13) for 13 weeks. Int J Toxicol 1997, 16:611-623.

157. Takahashi H, Yang S, Fujiki M, Kim M, Yamamoto T, Greenberg N: Toxocity studies of partially hydrolyzed guar gum. J Am Coll Toxicol 1994, 13:273-278.

158. Kuroiwa $Y$, Nishikawa A, Imazawa $T$, Kanki K, Kitamura $Y$, Umemura $T$, et al: Lack of subchronic toxicity of an aqueous extract of Agaricus blazei Murrill in F344 rats. Food Chem Toxicol 2005, 43:1047-1053.

159. The safety of extended consumption of freezing dryness Agaricus blazei (Iwade strain 101) himematsutake. Yakuri to Chiryo 2006, 34:103-117.

160. Tsuneo K, Takahiko N, Takashi F, Masaaki O, Michitaka S, Ahikiro S, et al: Single dose toxicity study of powdered Grifola frondosa by oral administration in rats. Pharmacometrics 2003, 65:39-41.

161. Han YS, Park SY, Choi BK, Choung SY: Acute oral toxicity studies of extract of sanghwang mushroom (Phellinus linteus). J Appl Pharmacol 2001, 9:46-50.

162. Cheng K-F, Leung P-C: General review of polysaccharopeptides (PSP) from C. versicolor: pharmacological and clinical studies. Cancer Therapy 2008, 6:117-130.

163. Sinnott RA, Ramberg J, Kirchner JM, Oubre C, Duncan C, Boyd S, et al: Utilization of arabinogalactan, aloe vera gel polysaccharides, and a mixed saccharide dietary supplement by human colonic bacteria in vitro. Int J Probiotics Prebiotics 2007, 2:97-104.

164. Salyers AA, Arthur R, Kuritza A: Digestion of larch arabinogalactan by a strain of human colonic Bacteroides growing in continuous culture. Agric Food Chem 1981, 29:475-480.

165. Salyers AA, Vercellotti JR, West SE, Wilkins TD: Fermentation of mucin and plant polysaccharides by strains of Bacteroides from the human colon. Appl Environ Microbiol 1977, 33:319-322.

166. Salyers AA: Breakdown of polysaccharides by human intestinal bacteria. $J$ Environ Pathol Toxicol Oncol 1985, 5:211-231.

167. Crociani F, Alessandrini A, Mucci MM, Biavati B: Degradation of complex carbohydrates by Bifidobacterium spp. Int J Food Microbiol 1994, 24:199-210.

168. Degnan BA, Macfarlane GT: Arabinogalactan utilization in continuous cultures of Bifidobacterium longum: Effect of co-culture with Bacteroides thetaiotaomicron. Anaerobe 1995, 1:103-112

169. Imamura L, Murai K, Zhao C-J, Takebe S, Kobashi K: Metabolism of arabinogalactan by rat and human intestinal microflora. BIFIDUS Flores, Fructus et Semina 1992, 6:19-29.

170. Michel C, Lahaye M, Bonnet C, Mabeau S, Barry JL: In vitro fermentation by human faecal bacteria of total and purified dietary fibres from brown seaweeds. Br J Nutr 1996, 75:263-280.

171. Okubo T, Ishihara N, Takahashi H, Fujisawa T, Kim M, Yamamoto T, et al: Effects of partially hydrolyzed guar gum intake on human intestinal microflora and its metabolism. Biosci Biotech Biochem 1994, 58:1364-1369.

172. Deville C, Gharbi M, Dandrifosse G, Peulen O: Study on the effects of laminarin, a polysaccharide from seaweed, on gut characteristics. I Sci Food Agric 2007, 87:1717-1725.

173. Ikuzawa M, Matsunaga K, Nishiyama S, Nakajima S, Kobayashi Y, Andoh T, et al: Fate and distribution of an antitumor protein-bound polysaccharide PSK (Krestin). Int J Immunopharmacol 1988, 10:415-423.

174. Yagi A, Hamano S, Tanaka T, Kaneo Y, Fujioka T, Mihashi K: Biodisposition of FITC-labeled aloemannan in mice. Planta Med 2001, 67:297-300.

175. Marzorati M, Verhelst A, Luta G, Sinnott R, Verstraete W, Van de Wiele T, et al: In vitro modulation of the human gastrointestinal microbial community by plant-derived polysaccharide-rich dietary supplements. Int J Food Microbiol 2010, 139:168-176.

176. Salyers AA, West SE, Vercellotti JR, Wilkins TD: Fermentation of mucins and plant polysaccharides by anaerobic bacteria from the human colon. Appl Environ Microbiol 1977, 34:529-533.

doi:10.1186/1475-2891-9-54

Cite this article as: Ramberg et al:: Immunomodulatory dietary

polysaccharides: a systematic review of the literature. Nutrition Journal 2010 9:54.

\section{Submit your next manuscript to BioMed Central and take full advantage of:}

- Convenient online submission

- Thorough peer review

- No space constraints or color figure charges

- Immediate publication on acceptance

- Inclusion in PubMed, CAS, Scopus and Google Scholar

- Research which is freely available for redistribution
Biomed Central 